\title{
Evaluación Docente de los Profesores de Religión Católica en Chile
}

\section{TeACHER ASSESSMENT OF THE CATHOLIC RELIGION TEACHERS IN CHILE}

\author{
Rolando Soto Bustos ${ }^{8}$ \\ Vicaría para la Educación del Arzobispado de Santiago \\ Santiago, Chile
}

\begin{abstract}
Resumen
El siguiente artículo presenta los resultados de un estudio sobre la evaluación docente de profesores de Religión Católica en Chile. Los datos proporcionados por el Ministerio de Educación (MINEDUC) son organizados y sistematizados permitiendo observar las distintas cohortes que se han evaluado a nivel país, por región y especialmente en el Arzobispado de Santiago. Los resultados son analizados críticamente desde una perspectiva pedagógica que permita a los profesores encontrar pistas que apunten a mejorar los aspectos deficitarios. Por otro lado, se desprenden algunas consecuencias que involucran a las universidades y agentes que acompañan a los profesores de Religión.
\end{abstract}

\section{Palabras claves}

Evaluación docente, profesor de religión católica, mejoramiento pedagógico, Religión, Formación inicial.

\section{Abstract}

The following article shows the results of a study of the assessment of Catholic religion teachers in Chile. The data provided by the Ministry of Education, MINEDUC, was organized and systematized in order to observe the range of cohorts that have been assessed nationwide in different regions and, especially, in Santiago's Archbishopric. The results were critically analyzed from a pedagogical perspective, which allows teachers to find hints that aim at improving defective aspects. On the other hand, it can be seen that there are some results that involve the universities and agents related to Religion teachers.

\section{KeY WORDS}

Teacher assessment, Catholic religion teacher, pedagogical improvement, Religion, teacher education 
Rolando Soto Bustos | Evaluación Docente de los Profesores de Religión Católica en Chile

\section{INTRODUCCIÓN}

El año 2013 la Vicaría para la Educación (VED) del Arzobispado de Santiago elaboró un informe sobre la evaluación docente (ED) que compartió con diferentes instituciones de educación superior responsables de formar profesores de Religión. Fruto de esta situación nació una alianza entre la VED y la Universidad Finis Terrae que respondió otorgando un Diplomado en las áreas de estudio más deficitarias, según el informe presentado, relacionadas con la planificación y evaluación de aprendizajes.

Pasados cinco años no se han vuelto a tener nuevos antecedentes que permitan observar la trayectoria de esta evaluación en el sector, aunque todos los ańos la Vicaría realiza actividades conducentes a apoyar a los docentes que serán evaluados.

La ausencia de datos duros motivó la petición al MINEDUC de los resultados para investigar y sistematizar la trayectoria de la ED de los profesores de religión católica. Junto con esta sistematización se realizó una revisión de fuentes bibliográficas proporcionadas por el portal de MIDE UC', organismo responsable de la confección y corrección de los instrumentos.

En la primera parte se revisan los resultados de la ED sistematizados como país y por regiones. Se observa la participación de hombres y mujeres, los niveles en que son evaluados y los resultados de los diferentes instrumentos de la ED.

En la segunda parte se hace una presentación más minuciosa de las comunas del Arzobispado de Santiago. Para ayudar a interpretar los datos se agruparon las comunas según las zonas pastorales de la arquidiócesis. Esta forma arbitraria de ordenarlas responde a la manera en que la Vicaría ha ido interviniendo en el territorio.

9 Organismo de la Pontificia Universidad Católica de Chile que desarrolla y aplica instrumentos de medición educacional en sus distintos niveles (preescolar, enseñanza básica, media y superior), tanto en el ámbito público como en el privado. Desde 2003, por encargo del Ministerio de Educación, implementa el Sistema de Evaluación del Desempeño Profesional Docente, evaluando cada ańo entre 15.000 y 20.000 docentes a lo largo de todo el país (N. del E.) 
En la última parte, se comentan algunas conclusiones, se comparten reflexiones y se abren interrogantes que permitan abrir el diálogo entre los actores involucrados.

\section{Resultados de la Evaluación Docente en Profesores DE Religión Católica a Nivel NaCiOnal}

\section{Cantidad de profesores de religión evaluados}

Desde el año 2008 se han sometido a la Evaluación un total de 4.851 profesores. Es probable que algunos docentes la hayan dado más de una vez por algunos de los criterios que fija la Ley al respecto.

No se tienen los datos de profesores varones y mujeres entre 2008 y 2011, solamente las cifras globales. Considerando solamente las cifras entre 2012 y 2016, las mujeres son ampliamente mayoría (1.870), lo que representa el 69,2\%. En cambio, los varones son 833 , representando el 30,8\%.

El 81,2\% de los profesores evaluados se desempeñan en el segundo ciclo y el restante $18,8 \%$, en enseńanza media. No se tienen datos de profesores evaluados en el primer ciclo básico.

Tabla 1:

Número de profesores de Religión Católica evaluados en el país por nivel de enseñanza.

\begin{tabular}{|l|l|l|l|l|l|l|}
\hline Año & Hombres & Mujeres & $\mathrm{H}+\mathrm{M}$ & $\begin{array}{l}\text { Segundo } \\
\text { Ciclo }\end{array}$ & $\begin{array}{l}\text { Educación } \\
\text { Media }\end{array}$ & sumatoria \\
\hline 2016 & 182 & 388 & 570 & 472 & 98 & 570 \\
\hline 2015 & 123 & 224 & 347 & 267 & 80 & 347 \\
\hline 2014 & 150 & 338 & 488 & 409 & 79 & 488 \\
\hline 2013 & 165 & 348 & 513 & 367 & 146 & 513 \\
\hline 2012 & 213 & 572 & 785 & 672 & 113 & 785 \\
\hline 2011 & & & 204 & 181 & 23 & 204 \\
\hline 2010 & & & 246 & 187 & 59 & 246 \\
\hline 2009 & & & 519 & 305 & 214 & 519 \\
\hline 2008 & & & 1179 & 1080 & 99 & 1179 \\
\hline TOTAL & 833 & 1870 & 4851 & 3940 & 911 & 4851 \\
\hline
\end{tabular}


Rolando Soto Bustos | Evaluación Docente de los Profesores de Religión Católica en Chile

\section{Distribución de profesores en el país}

Considerando los datos entregados por el MINEDUC entre 2012 y 2016, el 25,5\% de los profesores evaluados corresponden a la Región Metropolitana. Luego, las regiones con más profesores evaluados son la VIII Región (13,4\%), la V Región (9,3\%), la VI Región (9,1\%). Estas cuatro regiones concentran un poco más de la mitad de los profesores de religión del total de evaluados.

Las regiones con menos profesores evaluados son la XI Región $(0,9 \%)$, la I Región $(1,4 \%)$, la XV Región $(1,7 \%)$, la XII $(1,8 \%)$ y la XIV (2,4\%). Exceptuando la XIV, se caracterizan por ser regiones extremas del país. Por otro lado, en estas regiones no hay universidades católicas, por lo tanto son profesores cuya formación inicial la han tenido que hacer fuera de su región.

Tabla 2:

Distribución por regiones de profesores de religión evaluados entre 2016 y 2012.

\begin{tabular}{|c|c|c|c|c|c|c|c|c|c|c|c|c|c|c|c|c|c|c|}
\hline & \multicolumn{3}{|c|}{2016} & \multicolumn{3}{|c|}{2015} & \multicolumn{3}{|c|}{2014} & \multicolumn{3}{|c|}{2013} & \multicolumn{3}{|c|}{2012} & \multicolumn{3}{|c|}{ total } \\
\hline $\begin{array}{l}\text { 음 } \\
\text { 똔 }\end{array}$ & $\mathrm{H}$ & M & $\sum_{ \pm}^{\sum_{ \pm}}$ & $\mathrm{H}$ & M & $\sum_{ \pm}$ & H & M & $\sum_{ \pm}$ & $\mathrm{H}$ & M & $\sum_{ \pm}$ & $\mathrm{H}$ & M & $\sum_{ \pm}$ & $\mathrm{H}$ & $M$ & $\begin{array}{l}\bar{\pi} \\
\text { 䙲 }\end{array}$ \\
\hline 1 & 4 & 5 & 9 & 3 & 4 & 7 & & 1 & 1 & 4 & 6 & 10 & 3 & 7 & 10 & 14 & 23 & 37 \\
\hline$\|$ & 5 & 15 & 20 & 8 & 9 & 17 & 5 & 20 & 25 & 8 & 23 & 31 & 5 & 28 & 33 & 31 & 95 & 126 \\
\hline III & 6 & 21 & 27 & & 4 & 4 & 1 & 11 & 12 & 2 & 6 & 8 & 2 & 16 & 18 & 11 & 58 & 69 \\
\hline IV & 11 & 22 & 33 & 7 & 14 & 21 & 9 & 28 & 37 & 7 & 24 & 31 & 14 & 47 & 61 & 48 & 135 & 183 \\
\hline V & 17 & 39 & 56 & 10 & 26 & 36 & 11 & 28 & 39 & 15 & 32 & 47 & 20 & 54 & 74 & 73 & 179 & 252 \\
\hline $\mathrm{Vl}$ & 16 & 44 & 60 & 4 & 12 & 16 & 6 & 32 & 38 & 8 & 31 & 39 & 21 & 72 & 93 & 55 & 191 & 246 \\
\hline VII & 17 & 28 & 45 & 8 & 26 & 34 & 14 & 28 & 42 & 11 & 28 & 39 & 13 & 26 & 39 & 63 & 136 & 199 \\
\hline VII & 18 & 60 & 78 & 14 & 27 & 41 & 14 & 30 & 44 & 27 & 57 & 84 & 28 & 87 & 115 & 101 & 261 & 362 \\
\hline IX & 9 & 22 & 31 & 5 & 11 & 16 & 10 & 27 & 37 & 11 & 24 & 35 & 8 & 31 & 39 & 43 & 115 & 158 \\
\hline$x$ & 17 & 22 & 39 & 10 & 13 & 23 & 16 & 32 & 48 & 11 & 26 & 37 & 18 & 31 & 49 & 72 & 124 & 196 \\
\hline XI & 1 & 4 & 5 & & 1 & 1 & 2 & 2 & 4 & 2 & 5 & 7 & 1 & 6 & 7 & 6 & 18 & 24 \\
\hline XII & 5 & 3 & 8 & 2 & 10 & 12 & 3 & 7 & 10 & 2 & 5 & 7 & 3 & 10 & 13 & 15 & 35 & 50 \\
\hline RM & 46 & 89 & 135 & 46 & 56 & 102 & 55 & 82 & 137 & 49 & 64 & 113 & 65 & 137 & 202 & 261 & 428 & 689 \\
\hline XIV & 5 & 6 & 11 & 3 & 5 & 8 & 1 & 7 & 8 & 7 & 12 & 19 & 6 & 12 & 18 & 22 & 42 & 64 \\
\hline$x V$ & 5 & 8 & 13 & 3 & 6 & 9 & 3 & 3 & 6 & 1 & 5 & 6 & 2 & 12 & 14 & 14 & 34 & 48 \\
\hline & 182 & 388 & 570 & 123 & 224 & 347 & 150 & 338 & 488 & 165 & 348 & 513 & 209 & 576 & 785 & 829 & 1874 & 2703 \\
\hline
\end{tabular}




\section{Niveles de enseñanza en los cuales se desempeñan}

En la tabla 3 se observa que la mayoría de los profesores evaluados se desempeñan en el segundo ciclo (80,7\%). También se observa que hay regiones en las cuales casi no hay profesores que se desempeñan en la Educación Media, por ejemplo, en la XI, I, III y XV.

Tabla 3:

Niveles de enseñanza en los cuales se desempeñan los profesores evaluados entre 2012 y 2016.

\begin{tabular}{|c|c|c|c|c|c|c|c|c|c|c|c|c|}
\hline & \multicolumn{2}{|c|}{2016} & \multicolumn{2}{|c|}{2015} & \multicolumn{2}{|c|}{2014} & \multicolumn{2}{|c|}{2013} & \multicolumn{2}{|c|}{2012} & & \\
\hline REGION & SC & EM & SC & EM & SC & EM & SC & EM & SC & EM & SC & EM \\
\hline 1 & 8 & 1 & 5 & 2 & 1 & & 7 & 3 & 9 & 1 & 30 & 7 \\
\hline II & 17 & 3 & 11 & 6 & 18 & 7 & 18 & 13 & 31 & 2 & 95 & 31 \\
\hline III & 25 & 2 & 4 & & 10 & 2 & 7 & 1 & 16 & 2 & 62 & 7 \\
\hline IV & 28 & 5 & 17 & 4 & 36 & 1 & 21 & 10 & 50 & 11 & 152 & 31 \\
\hline V & 48 & 8 & 26 & 10 & 32 & 7 & 35 & 12 & 60 & 14 & 201 & 51 \\
\hline VI & 48 & 12 & 14 & 2 & 32 & 6 & 26 & 13 & 77 & 16 & 197 & 49 \\
\hline VII & 38 & 7 & 25 & 9 & 36 & 6 & 28 & 11 & 32 & 7 & 159 & 40 \\
\hline VII & 65 & 13 & 35 & 6 & 39 & 5 & 62 & 22 & 100 & 15 & 301 & 61 \\
\hline IX & 24 & 7 & 13 & 3 & 30 & 7 & 24 & 11 & 33 & 6 & 124 & 34 \\
\hline$x$ & 32 & 7 & 19 & 4 & 37 & 11 & 29 & 8 & 33 & 16 & 150 & 46 \\
\hline$X I$ & 4 & 1 & 1 & & 4 & & 6 & 1 & 7 & & 22 & 2 \\
\hline XII & 5 & 3 & 9 & 3 & 9 & 1 & 4 & 3 & 10 & 3 & 37 & 13 \\
\hline RM & 106 & 29 & 73 & 29 & 113 & 24 & 80 & 33 & 188 & 14 & 560 & 129 \\
\hline XIV & 9 & 2 & 8 & & 6 & 2 & 15 & 4 & 14 & 4 & 52 & 12 \\
\hline XV & 10 & 3 & 7 & 2 & 6 & & 5 & 1 & 12 & 2 & 40 & 8 \\
\hline & 467 & 103 & 267 & 80 & 409 & 79 & 367 & 146 & 672 & 113 & 2182 & 521 \\
\hline
\end{tabular}

\section{Resultados de la Evaluación Docente por cada instrumento}

Antes de presentar los resultados de la ED, es necesario precisar que éstos no admiten interpretaciones directas respecto de una mejora o deterioro del desempeño en el tiempo, aunque conserve su estructura y aspectos por evaluar. El rendimiento corresponde a cohortes distintas 
en términos de individuos que la integran, como de los niveles en que ejercen. Por otro lado, cada cohorte incluye un número de docentes que se re evalúa por haber pasado cuatros años, desde que la dio o por haber obtenido un resultado Insatisfactorio en el año anterior (Yun, Correa, Zapata y Carrasco, 2011).

Por otro lado, también es necesario puntualizar que la ED se realiza sobre la base de evidencias de desempeño recogidas a través de cuatro instrumentos: Autoevaluación, Entrevista por un Evaluador Par, Informes de Referencia de Terceros y Portafolio de desempeño pedagógico.

En una puntuación de 1 a 4, siendo 1 el nivel inferior y 4 el superior, la Autoevaluación es el instrumento con mejor resultado. Este resultado es coincidente con los datos a nivel nacional de las demás asignaturas. La autoevaluación pretende que el profesor reflexione sobre su propia práctica en relación con los estándares propuestos en el Marco para la Buena Enseñanza (MBE). Al parecer no es indicador muy confiable por sí mismo respecto de la práctica docente, dado que además la evaluación tiene consecuencias para avanzar en los tramos. Sin embargo, es un factor a considerar dentro del conjunto de la ED.

A continuación, la Entrevista de un Evaluador Par y el Informe de Referencia de Terceros contienen indicadores inferiores a la Autoevaluación, sin embargo, se encuentran sobre 2,50, que sería un valor esperado. Es relevante para la ED la referencia que otros colegas y profesionales de la educación pueden aportar al profesor para retroalimentar su práctica pedagógica. La literatura específica sobre este tema advierte sobre la fiabilidad del juicio de quienes observan. Algunos docentes del área han expresado, por ejemplo, que el evaluador par no era de la asignatura de Religión y se sintió perjudicado. Es relevante considerar que el docente siempre puede apelar ante la comisión comunal si tiene antecedentes respecto de un aspecto deficitario en la aplicación de algunos de los instrumentos. 
Finalmente, el instrumento más débil en la evaluación es el Portafolio, que se encuentra por debajo de lo esperado. Este resultado también coincide con la evidencia nacional e histórica de esta evaluación.

Tabla 4:

Promedio de los instrumentos de la evaluación docente de profesores de religión del país por año.

\begin{tabular}{|l|l|l|l|l|l|l|l|l|l|}
\hline & \multicolumn{7}{|c|}{ Promedio de los instrumentos por cada año. } \\
\hline Instrumentos & 2016 & 2015 & 2014 & 2013 & 2012 & 2011 & 2010 & 2009 & 2008 \\
\hline Autoevaluación & 3,84 & 3,79 & 3,83 & 3,81 & 3,86 & 3,81 & 3,84 & 3,84 & 3,89 \\
\hline Entrevista par & 2,85 & 2,74 & 2,73 & 3,08 & 3,11 & 2,99 & 2,82 & 2,79 & 2,80 \\
\hline $\begin{array}{l}\text { Informe } \\
\text { Referencia } \\
\text { Terceros }\end{array}$ & 2,82 & 2,67 & 2,71 & 2,68 & 2,72 & 2,63 & 2,52 & 2,92 & 2,93 \\
\hline Portafolio & 2,45 & 2,09 & 2,20 & 2,12 & 2,09 & 2,11 & 2,03 & 2,03 & 2,23 \\
\hline
\end{tabular}

\section{Resultados del portafolio}

La ED busca que los profesores puedan reflexionar sobre su práctica pedagógica. Para ello se utiliza una batería de instrumentos que, en su conjunto, otorgan evidencias que consideran una amplitud de situaciones en las cuales el profesor interviene.

Ya se ha visto que el portafolio es el instrumento que más incide en la evaluación por cuanto recoge información auténtica de lo que el profesor realiza en el aula.

En la tabla 5 se pueden observar las dimensiones medidas y las puntuaciones de los profesores evaluados entre 2012 y 2015 . El portafolio en años anteriores a 2012 tenía 8 dimensiones, y para efectos de observar el comportamiento general se seleccionaron los últimos años. 
Rolando Soto Bustos | Evaluación Docente de los Profesores de Religión Católica en Chile

Tabla 5:

Dimensiones medidas en el portafolio y puntajes obtenidos entre 2012 y 2015 de los profesores de religión del país

\begin{tabular}{|l|l|l|l|l|}
\hline & 2015 & 2014 & 2013 & 2012 \\
\hline Organización de la unidad & 2,09 & 2,29 & 2,21 & 2,09 \\
\hline Análisis de la clase & 1,81 & 1,95 & 1,92 & 1,71 \\
\hline Calidad de la Evaluación & 1,63 & 2,03 & 1,78 & 1,85 \\
\hline Reflexión a partir de la Evaluación & 1,68 & 1,81 & 1,69 & 1,72 \\
\hline Ambiente de la clase & 2,73 & 2,70 & 2,68 & 2,69 \\
\hline Estructura de la clase & 2,52 & 2,40 & 2,38 & 2,38 \\
\hline Interacción Pedagógica & 2,17 & 2,21 & 2,15 & 2,17 \\
\hline
\end{tabular}

Las cuatro primeras dimensiones corresponden al módulo $1 \mathrm{del}$ portafolio y las siguientes dimensiones a la clase grabada.

En el gráfico 1 de barras se observan las puntuaciones de cada dimensión por año. En las últimas cuatro mediciones el ambiente de clase se destaca por tener las puntuaciones más altas. Sus promedios se encuentran sobre el 2,5 puntaje considerado el nivel esperado.

Gráfico 1:

Resultados de las dimensiones del portafolio entre los años 2012 y 2015 en los profesores de religión del país

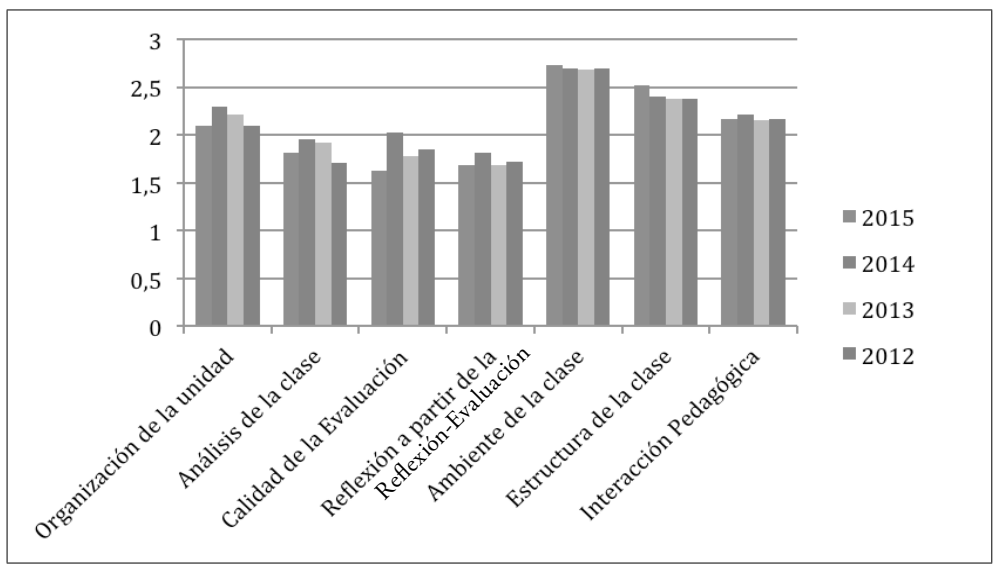


La dimensión más baja es la Reflexión sobre la Evaluación, seguida de la Calidad de la Evaluación. Ambas dimensiones se relacionan con un aspecto muy sensible para la asignatura ya que los resultados no inciden en la promoción de los estudiantes. En reiterados encuentros los profesores han demandado que la asignatura tenga una evaluación que incida en la promoción de los estudiantes. Esto es coincidente con la Encuesta Nacional aplicada a los profesores de Religión por parte de la Comisión de trabajo para la mejora de la EREC en Chile (2017), en la que se señala que la mayoría de los profesores del país espera que la nota en Religión sí incida en la promoción de los estudiantes.

Una hipótesis que explica los resultados en este aspecto de la ED podría deberse a que los profesores elaboran instrumentos evaluativos convencionales, como el de las demás asignaturas, cuando Religión no tiene una calificación. O los instrumentos no son los adecuados y se requiere mayor investigación, o los que se usan crean resistencia en los estudiantes que no ven la necesidad de prepararse para ellos. También es cierto que, por lo general, los Jefes de UTP de los colegios no revisan suficientemente las evaluaciones que hacen los docentes de Religión, ya que no tiene mayor importancia para el rendimiento. Esto dejaría al profesor de Religión sin retroalimentación para mejorar sus instrumentos, como señalaba una profesora de Lo Prado, consultada.

Herrada y Zapata (2015), respecto del bajo desempeńo de los profesores en general de la dimensión sobre la reflexión a partir de la evaluación, señalan que "los docentes deben demostrar su capacidad para retroalimentar a sus alumnos con la suficiente especificidad para que logren una mejoría en sus aprendizajes y demostrar además que comprenden el efecto que tienen las decisiones pedagógicas del docente en los aprendizajes logrados" (p.3). Si este fuera el consejo para los profesores de Religión, habría que tratar de entender mejor qué se entiende por aprendizaje en la asignatura. Si el aprendizaje fuera creer en Dios, en la trascendencia o en la acción del Espíritu Santo, probablemente habría que hacerse la pregunta inicial si el estudiante tiene fe. La confesionalidad en la clase de Religión juega un rol sobre los posibles aprendizajes de los estudiantes. En un plano 
más doctrinal se podría indicar a un estudiante que su respuesta ante una pregunta no corresponde con la tradición de la Iglesia. El comentario del profesor estaría acertado, pero si para el estudiante no tiene importancia entonces los resultados del instrumento serían negativos. El jefe de la UTP le podría decir que cambie el instrumento para evaluar o, más allá aún, que revise el enfoque de la clase. Esto requiere más reflexión ya que no se está teniendo un buen resultado en este aspecto de manera categórica.

El resto de las dimensiones se encuentran por debajo de lo esperado $(2,5)$, por lo que habría que señalar que los aspectos pedagógicos de los profesores de Religión se encuentran disminuidos.

\section{Evaluación del desempeño en el portafolio y final}

Como se ha dicho anteriormente, la evaluación del portafolio tiene mayor ponderación en la ED, pero que al combinarse con los demás instrumentos arroja el desempeño final de los profesores.

Tabla 6:

Profesores evaluados por años distribuidos por desempeño en el portafolio y luego de aplicar todos los instrumentos de la ED.

\begin{tabular}{|c|c|c|c|c|c|c|c|c|c|}
\hline \multirow[b]{2}{*}{ Año } & \multirow[b]{2}{*}{$\begin{array}{l}\text { Profesores } \\
\text { de Religión } \\
\text { católica } \\
\text { evaluados }\end{array}$} & \multicolumn{4}{|c|}{$\begin{array}{l}\text { N Profesores según desempeño en } \\
\text { el Portafolio. }\end{array}$} & \multicolumn{4}{|c|}{$\begin{array}{l}\text { Nº profesores al final de la } \\
\text { Evaluación Docente por niveles de } \\
\text { desempeño. }\end{array}$} \\
\hline & & I & B & C & D & I & B & C & D \\
\hline 2016 & 570 & 33 & 275 & 254 & 8 & 9 & 90 & 393 & 78 \\
\hline 2015 & 347 & 35 & 283 & 25 & & 11 & 178 & 149 & 5 \\
\hline 2014 & 488 & 29 & 386 & 72 & 1 & 17 & 177 & 282 & 12 \\
\hline 2013 & 513 & 55 & 408 & 49 & 1 & 16 & 184 & 288 & 25 \\
\hline 2012 & 785 & 85 & 658 & 42 & & 19 & 307 & 438 & 21 \\
\hline 2011 & 204 & & & & & 13 & 74 & 107 & 10 \\
\hline 2010 & 246 & & & & & 23 & 118 & 98 & 7 \\
\hline 2009 & 519 & & & & & 23 & 269 & 221 & 6 \\
\hline 2008 & 1179 & & & & & 19 & 431 & 660 & 69 \\
\hline Total & 4851 & 237 & 2010 & 442 & 10 & 150 & 1858 & 2636 & 233 \\
\hline$\%$ & & $8,8 \%$ & $74,4 \%$ & $16,4 \%$ & $0,4 \%$ & $3,1 \%$ & $37,7 \%$ & $54,3 \%$ & $4,8 \%$ \\
\hline
\end{tabular}


Respecto del desempeño de los profesores de Religión en el portafolio en todo el país desde el año 2012, se observa que el 16,8\% de los profesores obtiene un desempeño Competente o Destacado (tabla 8). Luego, el 83,2\% obtiene un desempeño Insuficiente o Básico. En el gráfico 2 se observa por año la distribución de los profesores por desempeño:

Gráfico 2:

Resultados de la evaluación del portafolio entre los años 2012 y 2015 en los profesores de religión del país.

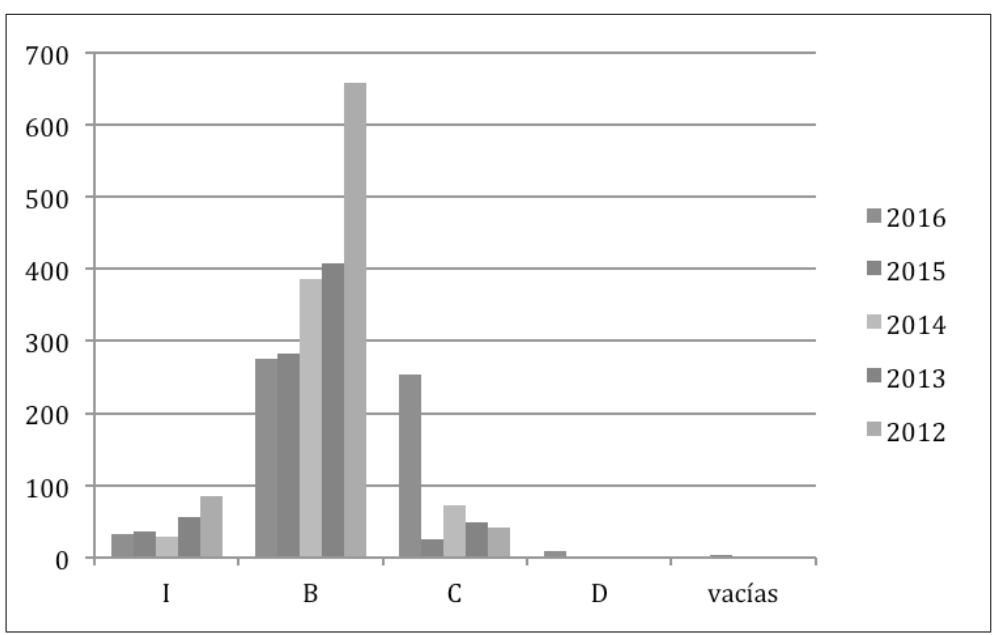

El desempeño Básico constituye la proporción más alta de los profesores evaluados con 2010 docentes de un total de 2703 (74,3\%). Entre los años 2012 y 2015, los profesores con desempeño Básico se mantienen alrededor del $80 \%$.

En el nivel de desempeño Insuficiente, en los años 2012, 2013 y 2015, las cifras bordean el 10\%. En los años 2014 y 2016 las proporciones se reducen a un 5,9\% y 5,8\%, respectivamente.

El desempeño Competente tuvo un aumento significativo en el año 2016, donde el 44,6\% de los profesores alcanzó este nivel. Este aumento también ocurrió en el nivel Destacado, aunque en el global solo 10 profesores alcanza este nivel $(0,3 \%)$. 
Rolando Soto Bustos | Evaluación Docente de los Profesores de Religión Católica en Chile

Si se observa el portafolio como una fotografía del momento, quizás los resultados sean bajos, pero en el global de la ED, aplicados todos los instrumentos, hay una movilidad de docentes de un nivel de desempeño a otro. Por ejemplo, en el nivel Competente hay un aumento del $57,3 \%$ con un total de 1550 docentes. Le sigue el nivel Básico con un 34,6\% con 936 profesores. El Insuficiente baja a 2.7\% y en el nivel Destacado hay un 5,2\% de profesores.

El mejoramiento en los resultados, respecto del Portafolio se produce por la ponderación de los demás instrumentos. El gráfico 3 representa este aspecto.

Gráfico 3:

Resultados de la ED final entre los años 2012 y 2015 en los profesores de religión del país.

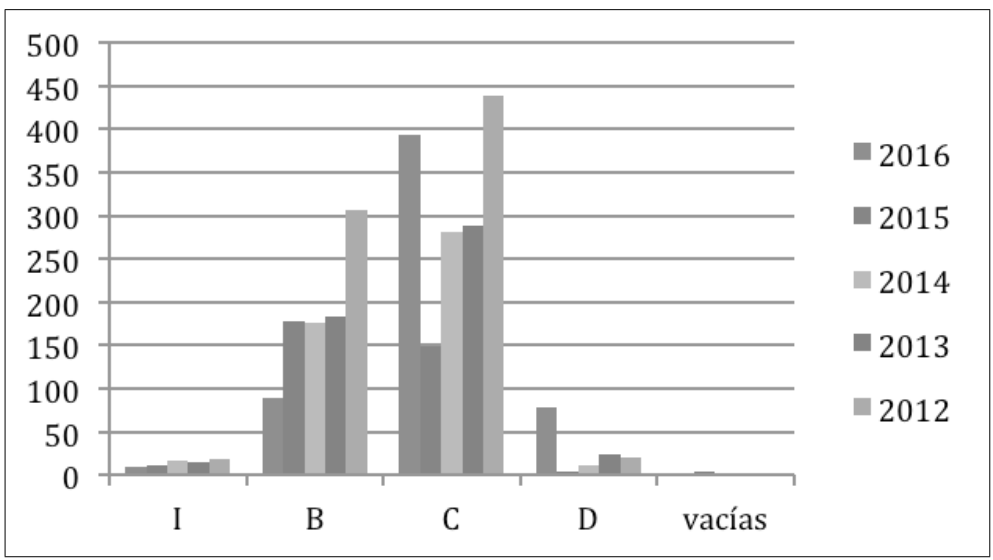

Es necesario remarcar que cuando se habla de ED se debe entender al conjunto de los instrumentos que la componen. Distinto es cuando solamente se consideran los resultados del Portafolio.

\section{Evaluación del desempeńo en el portafolio y final por regiones}

En términos generales, la Región Metropolitana (RM) concentra la mayor cantidad de profesores que se evalúan. Le siguen la $8^{\mathrm{a}}$, la $5^{\mathrm{a}}$ y la $6^{a}$ regiones. 
Tabla 7:

Profesores de religión por regiones evaluados según niveles de desempeño en el portafolio.

\begin{tabular}{|c|c|c|c|c|c|c|c|c|c|c|c|c|c|c|c|c|c|c|c|c|}
\hline & \multicolumn{4}{|c|}{2012} & \multicolumn{4}{|c|}{2013} & \multicolumn{4}{|c|}{2014} & \multicolumn{4}{|c|}{2015} & \multicolumn{4}{|c|}{2016} \\
\hline $\begin{array}{l}\text { 음 } \\
\underset{\varpi}{~}\end{array}$ & 1 & B & C & $D$ & 1 & $B$ & C & D & 1 & B & C & $\mathrm{D}$ & 1 & B & C & $D$ & 1 & B & C & $D$ \\
\hline 1 & & 10 & & & 4 & 6 & & & & 1 & & & 3 & 4 & & & 4 & 5 & & \\
\hline ॥ & 8 & 25 & & & 6 & 23 & 2 & & 2 & 22 & 1 & & 2 & 15 & & & 2 & 9 & 9 & \\
\hline III & 4 & 14 & & & & 8 & & & 1 & 8 & 3 & & & 4 & & & 1 & 17 & 9 & \\
\hline IV & 5 & 54 & 2 & & 3 & 25 & 3 & & 3 & 30 & 4 & & 1 & 18 & 2 & & 3 & 21 & 9 & \\
\hline V & 6 & 64 & 4 & & 3 & 38 & 6 & & 4 & 26 & 9 & & 2 & 31 & 2 & & 1 & 25 & 28 & 2 \\
\hline $\mathrm{VI}$ & 6 & 81 & 6 & & 4 & 32 & 3 & & 3 & 25 & 9 & 1 & & 15 & 1 & & 4 & 29 & 27 & \\
\hline VII & 6 & 33 & & & 3 & 33 & 3 & & 2 & 34 & 6 & & 3 & 28 & 3 & & 1 & 27 & 17 & \\
\hline VIII & 10 & 96 & 9 & & 5 & 69 & 10 & & 1 & 34 & 9 & & 3 & 33 & 5 & & 1 & 33 & 43 & 1 \\
\hline IX & 2 & 37 & & & 3 & 30 & 2 & & 4 & 27 & 6 & & 1 & 14 & & & 3 & 9 & 19 & \\
\hline$x$ & 8 & 41 & & & 6 & 30 & 1 & & 2 & 44 & 2 & & 3 & 18 & 2 & & 2 & 21 & 16 & \\
\hline XI & & 7 & & & & 6 & 1 & & & 3 & 1 & & & 1 & & & & 1 & 4 & \\
\hline XII & 3 & 9 & 1 & & 1 & 5 & 1 & & & 8 & 2 & & 3 & 8 & 1 & & & 4 & 3 & 1 \\
\hline RM & 22 & 163 & 17 & & 16 & 83 & 13 & 1 & 7 & 111 & 19 & & 12 & 81 & 7 & & 11 & 58 & 62 & 4 \\
\hline XIV & 4 & 12 & 2 & & 1 & 14 & 4 & & & 7 & 1 & & & 7 & 1 & & & 5 & 6 & \\
\hline$X V$ & 1 & 12 & 1 & & & 6 & & & & 6 & & & 2 & 6 & 1 & & & 11 & 2 & \\
\hline & 85 & 658 & 42 & 0 & 55 & 408 & 49 & 1 & 29 & 386 & 72 & 1 & 35 & 283 & 25 & 0 & 33 & 275 & 254 & 8 \\
\hline$\%$ & 10,8 & 83,8 & 5,4 & 0,0 & 10,7 & 79,5 & 9,6 & 0,2 & 5,9 & 79,1 & 14,8 & 0,2 & 10,1 & 81,6 & 7,2 & 0,0 & 5,8 & 48,2 & 44,6 & 1,4 \\
\hline
\end{tabular}

Como se puede observar en la tabla 9, la tendencia de los últimos años en las regiones es hacia la disminución de profesores en el nivel Básico y el aumento de Competentes, a excepción del año 2015.

Otro dato es que se da una alta concentración de profesores entre la $4^{\mathrm{a}}$ y $10^{\mathrm{a}}$ región lo que lleva también a encontrar menos profesores Competentes y Destacados en las religiones extremas. Este fenómeno es muy particular en el caso de la $1^{\text {a }}$ región donde desde 2012 no hay docentes en estos niveles de desempeño en el portafolio. 
Rolando Soto Bustos | Evaluación Docente de los Profesores de Religión Católica en Chile

Tabla 10:

Profesores de religión por regiones según resultado final en la ED.

\begin{tabular}{|c|c|c|c|c|c|c|c|c|c|c|c|c|c|c|c|c|c|c|c|c|}
\hline & \multicolumn{4}{|c|}{2012} & \multicolumn{4}{|c|}{2013} & \multicolumn{4}{|c|}{2014} & \multicolumn{4}{|c|}{2015} & \multicolumn{4}{|c|}{2016} \\
\hline 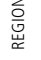 & 1 & B & C & D & 1 & B & c & $D$ & 1 & B & c & $D$ & 1 & B & c & D & 1 & B & c & D \\
\hline 1 & & 8 & 2 & & & 8 & 2 & & & 1 & & & & 6 & 1 & & 1 & 5 & 3 & \\
\hline$\|$ & 1 & 18 & 13 & 1 & 2 & 11 & 17 & 1 & 1 & 8 & 16 & & & 14 & 3 & & & 4 & 14 & 2 \\
\hline III & 1 & 11 & 6 & & & 5 & 3 & & 1 & 5 & 5 & 1 & & 2 & 2 & & & 7 & 16 & 4 \\
\hline IV & 1 & 22 & 37 & 1 & 1 & 11 & 19 & & 3 & 18 & 16 & & & 12 & 9 & & 1 & 6 & 23 & 3 \\
\hline v & 2 & 30 & 41 & 1 & & 15 & 32 & & 2 & 17 & 20 & & & 16 & 19 & & & 4 & 47 & 5 \\
\hline $\mathrm{VI}$ & 1 & 27 & 60 & 5 & & 9 & 28 & 2 & & 12 & 21 & 5 & & 8 & 7 & 1 & 2 & 8 & 40 & 10 \\
\hline VII & & 14 & 25 & & 2 & 7 & 24 & 6 & 1 & 13 & 27 & 1 & 2 & 12 & 20 & & 1 & 6 & 34 & 4 \\
\hline VIIII & 5 & 21 & 82 & 7 & & 26 & 53 & 5 & 1 & 8 & 33 & 2 & 2 & 15 & 23 & 1 & & 4 & 55 & 19 \\
\hline IX & & 13 & 26 & & 1 & 12 & 22 & & 2 & 14 & 20 & 1 & & 9 & 6 & & & 6 & 22 & 3 \\
\hline$x$ & 3 & 23 & 23 & & 3 & 16 & 17 & 1 & 2 & 18 & 28 & & 1 & 12 & 10 & & 1 & 5 & 32 & 1 \\
\hline XI & & 2 & 5 & & 1 & 1 & 5 & & 1 & 2 & 1 & & & 1 & & & & & 4 & 1 \\
\hline XII & 2 & 8 & 3 & & & 4 & 3 & & & 5 & 5 & & & 5 & 7 & & & 2 & 3 & 3 \\
\hline RM & 1 & $\mid 101$ & 95 & 5 & 5 & 51 & 19 & 8 & 3 & 52 & 80 & 2 & 6 & 57 & 35 & 2 & 3 & 28 & 84 & 20 \\
\hline XIV & 2 & 5 & 10 & 1 & 1 & 6 & 10 & 2 & & 2 & 6 & & & 2 & 5 & 1 & & 3 & 6 & 2 \\
\hline$x \mathrm{XV}$ & & 4 & 10 & & & 2 & 4 & & & 2 & 4 & & & 7 & 2 & & & 2 & 10 & 1 \\
\hline & 19 & 307 & 438 & 21 & 16 & 184 & 258 & 25 & 17 & 177 & 282 & 12 & 11 & 178 & 149 & 5 & 9 & 90 & 393 & 78 \\
\hline$\%$ & 2,4 & 39,1 & 55,8 & 2,7 & 3,1 & 35,9 & 50,3 & 4,9 & 3,5 & 36,3 & 57,8 & 2,5 & 3,2 & 51,3 & 42,9 & $\mid$\begin{tabular}{|l}
$\mid, 4$ \\
\end{tabular} & 1,6 & 15,8 & 68,9 & \begin{tabular}{|l|l}
13,7 \\
\end{tabular} \\
\hline
\end{tabular}

EVALUACIÓN DEL DESEMPEÑO EN EL PORTAFOLIO Y FINAL EN COMUNAS DEL ARZOBISPADO

\section{Número de profesores evaluados por comuna}

En esta sección del informe se van a presentar los datos de las comunas que componen el Arzobispado de Santiago. La Región Metropolitana está compuesta de 52 comunas, de las cuales en 37 de ellas la Vicaría otorga certificados de idoneidad a los profesores de Religión. El resto corresponde a comunas de diócesis vecinas (San Bernardo, Melipilla y San Felipe). 
Para efectos del estudio se deja fuera la comuna de La Pintana, donde el Arzobispado tiene una pequeña porción. De los colegios que dependen del Arzobispado ninguno es del sistema municipal. De esta forma el informe trabaja con 36 comunas.

De las 36 comunas estudiadas, solo en 18 de ellas los profesores han sido evaluados entre los años 2012-2016. Destacan las comunas de Santiago y Puente Alto como aquellas que concentran la mayor cantidad de docentes evaluados (101 de 508 en los años estudiados).

Las comunas de La Florida, Recoleta, Pudahuel y Maipú tienen más de 25 y menos de 30 docentes evaluados. En el otro extremo, las comunas con menos profesores evaluados son Cerrillos, Las Condes y San José de Maipo con 4 docentes en el mismo lapso de tiempo. Por último, la comuna con menos evaluaciones es Til Til, donde solamente se ha evaluado docentes en el año 2012 y 2015.

Estos datos revelan la escasa presencia de profesores de Religión en el sistema municipal, debido probablemente a la disminución de la matrícula, entre algunos factores. En términos globales, descontando las comunas con más de 25 docentes evaluados en el período, en 30 comunas se evalúan menos de 4 profesores por año. Si consideramos que en la Zona Sur existen 96 escuelas y liceos, y los profesores evaluados han sido 74, no alcanza a haber uno por cada establecimiento. En el centro, la comuna de Santiago tiene 37 establecimientos y se han evaluado 51 profesores.

Más allá de los resultados de la ED, las cifras de participación de profesores en el sistema municipal están señalando una voz de alerta respecto de la presencia de la Iglesia en lugares donde el profesor(a) es la única voz que algunos estudiantes podrían escuchar de hablar de Dios.

La baja de profesores de Religión católica puede deberse también a las exigencias ministeriales de contratar a docentes de otras confesiones, abriendo la posibilidad de elección de las familias. En otras ocasiones, puede ser que algunos colegios y liceos pidan a los apoderados renunciar a la clase de Religión para proponer otras actividades. También hay que considerar que la matrícula en los 
Rolando Soto Bustos | Evaluación Docente de los Profesores de Religión Católica en Chile

colegios municipales ha bajado, no siendo necesaria la contratación de más profesores de Religión.

Cualquiera sea el motivo de la baja de profesores de Religión en el sector municipal, la reflexión que es necesario hacer es sobre la pertinencia de la asignatura en los colegios que reciben financiamiento público. Los bajos niveles en la ED de los profesores de Religión están dando una señal de que los docentes que imparten la asignatura no tienen la suficiente preparación pedagógica para impartir la enseñanza.

La Vicaría ha hecho una opción por clarificar el aporte de la escuela católica en la sociedad conforme a los lineamientos de la Congregación para la Educación Católica, pero se hace necesario distinguir la escuela católica de la formación católica. Llama la atención que la Vicaría atienda a los profesores de Religión especialmente, pero no considere a los demás educadores en sus planes de formación y acompańamiento.

\section{Resultados por zonas}

En los siguientes cuadros se resume la información de puntajes promedios en cada uno de los instrumentos de la $\mathrm{ED}$ y el número de profesores en cada uno de los niveles de desempeño, tanto del portafolio como del resultado final.

Las comunas se han agrupado por zonas pastorales para permitir una mirada que responde al plan elaborado por el Área de Pedagogía en Religión de la Vicaría. 
Tabla 11:

Promedios por instrumentos y número de profesores por desempeño en portafolio y ED final Zona Centro.

\begin{tabular}{|c|c|c|c|c|c|c|c|c|c|c|c|c|c|c|c|c|}
\hline \multicolumn{3}{|c|}{ ZONA CENTRO } & \multirow[b]{2}{*}{ 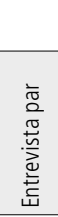 } & \multirow[b]{2}{*}{ 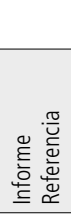 } & \multirow[b]{2}{*}{$\begin{array}{l}\frac{.}{0} \\
\frac{0}{0} \\
\frac{\pi}{0} \\
\frac{0}{0} \\
\frac{0}{0} \\
\frac{0}{2}\end{array}$} & \multicolumn{5}{|c|}{ desempeño portafolio } & & \multicolumn{5}{|c|}{ desempeño final } \\
\hline & 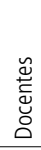 & 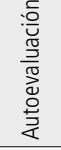 & & & & - & $\infty$ & $\cup$ & 0 & 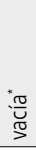 & 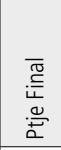 & - & $\infty$ & $u$ & 0 & $\begin{array}{l}\frac{\pi}{0} \\
\frac{\pi}{5}\end{array}$ \\
\hline 2016 & 9 & 3,55 & 2,77 & 2,77 & 2,47 & & 5 & 4 & & & 2,67 & & 2 & 6 & 1 & \\
\hline 2015 & 20 & 3,84 & 3,05 & 2,47 & 2,12 & 2 & 16 & 1 & & 1 & 2,51 & & 8 & 11 & & 1 \\
\hline 2014 & 10 & 3,9 & 2,5 & 3,1 & 2,28 & 1 & 7 & 2 & & & 2,57 & & 3 & 7 & & \\
\hline 2013 & 2 & 3,5 & 3,5 & 3 & 1,92 & 1 & 1 & & & & 2,5 & & 1 & 1 & & \\
\hline 2012 & 10 & 3,8 & 3,4 & 2,7 & 2,12 & 1 & 9 & & & & 2,6 & & 5 & 5 & & \\
\hline & 51 & & & & & 5 & 38 & 7 & 0 & 1 & & 0 & 19 & 30 & 1 & 1 \\
\hline
\end{tabular}

Tabla 12:

Promedios por instrumentos y número de profesores por desempeño en portafolio y ED final Zona Cordillera.

\begin{tabular}{|c|c|c|c|c|c|c|c|c|c|c|c|c|c|c|c|c|}
\hline \multicolumn{3}{|c|}{ ZONA CORDILLERA } & \multirow[b]{2}{*}{ 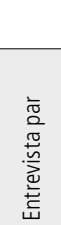 } & \multirow[b]{2}{*}{ 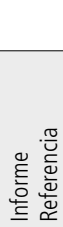 } & \multirow[b]{2}{*}{$\begin{array}{l}\frac{.0}{0} \\
\frac{0}{0} \\
\frac{0}{0} \\
0 \\
\frac{0}{0} \\
\frac{0}{0}\end{array}$} & \multicolumn{5}{|c|}{ desempeño portafolio } & & \multicolumn{5}{|c|}{ desempeño final } \\
\hline & 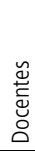 & 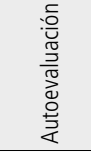 & & & & - & $\infty$ & $\cup$ & 0 & 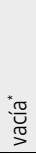 & 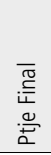 & - & $\infty$ & $u$ & 0 & $\begin{array}{l}\frac{\pi}{\mathscr{T}} \\
\frac{\pi}{7}\end{array}$ \\
\hline 2016 & 12 & 3.7 & 3,34 & 2,84 & 2.66 & 0 & 5 & 5 & 2 & & 2,92 & 0 & 0 & 7 & 5 & \\
\hline 2015 & 5 & 3,62 & 3 & 3 & 2,41 & 0 & 4 & 1 & 0 & & 2,71 & 0 & 0 & 4 & 1 & \\
\hline 2014 & 10 & 3,75 & 2,71 & 2,46 & 2,22 & 0 & 7 & 3 & 0 & & 2,49 & 0 & 3 & 7 & 0 & \\
\hline 2013 & 11 & 3,37 & 3,01 & 2,5 & 1,94 & 1 & 7 & 3 & 0 & & 2,35 & 1 & 3 & 4 & 3 & \\
\hline 2012 & 8 & 3,79 & 3,12 & 2,91 & 2,18 & 0 & 8 & 0 & 0 & & 2,6 & 0 & 3 & 4 & 1 & \\
\hline & 46 & & & & & 1 & 31 & 12 & 2 & 0 & & 1 & 9 & 26 & 10 & 0 \\
\hline
\end{tabular}


Rolando Soto Bustos | Evaluación Docente de los Profesores de Religión Católica en Chile

Tabla 13:

Promedios por instrumentos y número de profesores por desempeño en portafolio y ED final Zona del Maipo.

\begin{tabular}{|c|c|c|c|c|c|c|c|c|c|c|c|c|c|c|c|c|}
\hline \multicolumn{3}{|c|}{ ZONA del MAIPO } & \multirow[b]{2}{*}{ 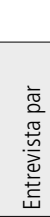 } & \multirow[b]{2}{*}{ 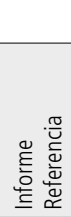 } & \multirow[b]{2}{*}{$\begin{array}{l}\frac{ㅇ}{0} \\
\frac{0}{0} \\
\frac{\pi}{0} \\
\frac{0}{0} \\
\stackrel{\Delta}{\square} \\
\frac{0}{0}\end{array}$} & \multicolumn{5}{|c|}{ desempeño portafolio } & & \multicolumn{5}{|c|}{ desempeño final } \\
\hline & 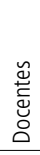 & 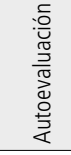 & & & & - & $\infty$ & $u$ & 0 & $\begin{array}{l}\frac{\pi}{4} \\
\frac{\pi}{\pi} \\
\end{array}$ & 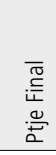 & - & $\infty$ & $\cup$ & 0 & \\
\hline 2016 & 10 & 3,83 & 2,72 & 2,27 & 2,31 & 2 & 2 & 6 & 0 & & 2,54 & 2 & 1 & 6 & 1 & \\
\hline 2015 & 6 & 3,66 & 2,5 & 2 & 2,05 & 2 & 3 & 1 & 0 & & 2,29 & 0 & 5 & 1 & 0 & \\
\hline 2014 & 16 & 3,83 & 2,86 & 2,6 & 2,12 & 1 & 12 & 3 & 0 & & 2,48 & 2 & 6 & 8 & 0 & \\
\hline 2013 & 6 & 3,66 & 2,83 & 2,33 & 2,33 & 0 & 5 & 0 & 1 & & 2,56 & 0 & 4 & 1 & 1 & \\
\hline 2012 & 16 & 3,46 & 2,92 & 2,39 & 2,03 & 2 & 12 & 2 & 0 & & 2,39 & 0 & 11 & 5 & 0 & \\
\hline & 54 & & & & & 7 & 34 & 12 & 1 & 0 & & 4 & 27 & 21 & 2 & 0 \\
\hline
\end{tabular}

Tabla 14:

Promedios por instrumentos y número de profesores por desempeño en portafolio y ED final Zona Norte

\begin{tabular}{|c|c|c|c|c|c|c|c|c|c|c|c|c|c|c|c|c|}
\hline \multicolumn{3}{|c|}{ ZONA NORTE } & \multirow[b]{2}{*}{ 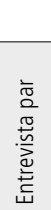 } & \multirow[b]{2}{*}{ 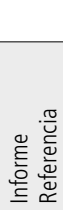 } & \multirow[b]{2}{*}{ 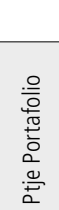 } & \multicolumn{5}{|c|}{ desempeño portafolio } & & \multicolumn{5}{|c|}{ desempeño final } \\
\hline & 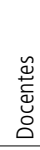 & 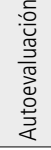 & & & & - & $\infty$ & $\cup$ & 0 & 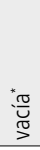 & 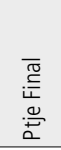 & - & $\infty$ & $\cup$ & 0 & \\
\hline 2016 & 19 & 3,86 & 2,78 & 2,36 & 2,43 & 2 & 9 & 8 & 0 & & 2,63 & 1 & 1 & 16 & 1 & \\
\hline 2015 & 24 & 3,68 & 2,52 & 2,5 & 1,95 & 5 & 18 & 0 & 0 & 1 & 2,29 & 3 & 18 & 2 & & 1 \\
\hline 2014 & 17 & 3,72 & 2,78 & 2,69 & 2,21 & 0 & 16 & 1 & 0 & & 2,52 & 0 & 7 & 10 & 0 & \\
\hline 2013 & 16 & 3,90 & 2,98 & 2,52 & 2,00 & 3 & 11 & 2 & 0 & & 2,43 & 2 & 7 & 6 & 1 & \\
\hline 2012 & 33 & 3,93 & 3,07 & 2,49 & 1,93 & 6 & 26 & 1 & 0 & & 2,41 & 0 & 20 & 13 & 0 & \\
\hline & 109 & & & & & 16 & 80 & 12 & 0 & 1 & & 6 & 53 & 47 & 2 & 1 \\
\hline
\end{tabular}


Tabla 15:

Promedios por instrumentos y número de profesores por desempeño en portafolio y ED final Zona Oeste

\begin{tabular}{|c|c|c|c|c|c|c|c|c|c|c|c|c|c|c|c|c|}
\hline \multicolumn{3}{|c|}{ ZONA OESTE } & \multirow[b]{2}{*}{ 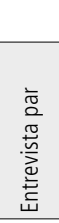 } & \multirow[b]{2}{*}{ 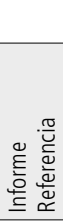 } & \multirow[b]{2}{*}{$\begin{array}{l}\frac{0}{0} \\
\frac{0}{0} \\
\frac{\pi}{0} \\
\frac{0}{2} \\
\frac{0}{ \pm}\end{array}$} & \multicolumn{5}{|c|}{ desempeño portafolio } & & \multicolumn{5}{|c|}{ desempeño final } \\
\hline & 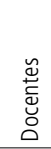 & 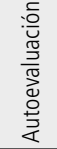 & & & & - & $\infty$ & $u$ & 0 & 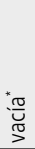 & 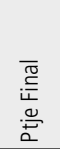 & - & $\infty$ & $u$ & 0 & : \\
\hline 2016 & 17 & 4 & 2,83 & 2,86 & 2,37 & 0 & 11 & 6 & 0 & & 2,67 & 0 & 6 & 9 & 2 & \\
\hline 2015 & 11 & 3,83 & 2,62 & 2,49 & 2,18 & 0 & 10 & 1 & 0 & & 2,43 & 0 & 6 & 4 & 1 & \\
\hline 2014 & 20 & 4 & 2,68 & 2,63 & 2,22 & 2 & 18 & 0 & 0 & & 2,51 & 0 & 8 & 12 & 0 & \\
\hline 2013 & 20 & 3,54 & 3,33 & 2,54 & 1,92 & 5 & 13 & 2 & 0 & & 2,42 & 1 & 9 & 10 & 0 & \\
\hline 2012 & 33 & 3,86 & 3,25 & 2,67 & 2,13 & 6 & 26 & 1 & 0 & & 2,57 & 0 & 18 & 14 & 1 & \\
\hline & 101 & & & & & 13 & 78 & 10 & 0 & 0 & & 1 & 47 & 49 & 4 & 0 \\
\hline
\end{tabular}

Tabla 16:

Promedios por instrumentos y número de profesores por desempeño en portafolio y ED final Zona Oriente

\begin{tabular}{|c|c|c|c|c|c|c|c|c|c|c|c|c|c|c|c|c|}
\hline \multicolumn{4}{|c|}{ ZONA ORIENTE } & \multirow[b]{2}{*}{ 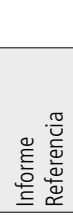 } & \multirow[b]{2}{*}{ 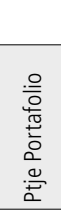 } & \multicolumn{5}{|c|}{ desempeño portafolio } & & \multicolumn{5}{|c|}{ desempeño final } \\
\hline & 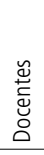 & 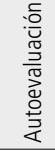 & 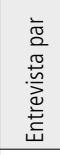 & & & - & $\infty$ & $\cup$ & 0 & 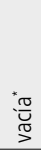 & 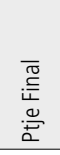 & - & $\infty$ & $\cup$ & 0 & $\begin{array}{l}\frac{\pi}{0} \\
\stackrel{0}{\pi}\end{array}$ \\
\hline 2016 & 13 & 3,68 & 2,87 & 2,77 & 2,50 & 2 & 5 & 4 & 2 & & 2,71 & 0 & 3 & 6 & 4 & \\
\hline 2015 & 13 & 3,70 & 2,51 & 2,39 & 2,13 & 1 & 12 & 0 & 0 & & 2,39 & 0 & 8 & 5 & 0 & \\
\hline 2014 & 10 & 4,00 & 2,26 & 2,13 & 2,30 & 1 & 6 & 3 & 0 & & 2,45 & 1 & 4 & 5 & 0 & \\
\hline 2013 & 18 & 3,70 & 2,72 & 2,29 & 2,08 & 2 & 14 & 2 & 0 & & 2,39 & 0 & 14 & 2 & 2 & \\
\hline \multirow[t]{2}{*}{2012} & 19 & 3,72 & 3,33 & 2,47 & 2,14 & 1 & 16 & 2 & 0 & & 2,56 & 0 & 7 & 11 & 1 & \\
\hline & 73 & & & & & 7 & 53 & 11 & 2 & 0 & & 1 & 36 & 29 & 7 & 0 \\
\hline
\end{tabular}


Rolando Soto Bustos | Evaluación Docente de los Profesores de Religión Católica en Chile

Tabla 17:

Promedios por instrumentos y número de profesores por desempeño en portafolio y ED final Zona Sur

\begin{tabular}{|c|c|c|c|c|c|c|c|c|c|c|c|c|c|c|c|c|}
\hline \multicolumn{3}{|c|}{ ZONA SUR } & \multirow[b]{2}{*}{ 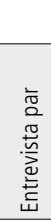 } & \multirow[b]{2}{*}{ 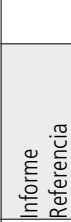 } & \multirow[b]{2}{*}{$\begin{array}{l}\frac{.}{0} \\
\frac{0}{0} \\
\frac{\pi}{0} \\
0 \\
0 \\
\frac{0}{2} \\
\frac{0}{2}\end{array}$} & \multicolumn{5}{|c|}{ desempeño portafolio } & & \multicolumn{5}{|c|}{ desempeño final } \\
\hline & 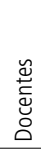 & 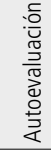 & & & & - & $\infty$ & $\cup$ & 0 & 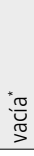 & 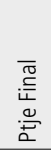 & - & $\infty$ & $\cup$ & 0 & $\begin{array}{l}\frac{\pi}{2} \\
\frac{\pi}{7}\end{array}$ \\
\hline 2016 & 17 & 3,7 & 2,9 & 2,61 & 2,49 & 2 & 8 & 7 & 0 & & 2,82 & 0 & 6 & 9 & 2 & \\
\hline 2015 & 7 & 3,30 & 2,3 & 2,3 & 2,05 & 1 & 6 & 0 & 0 & & 2,25 & 1 & 4 & 2 & 0 & \\
\hline 2014 & 18 & 3,61 & 2,87 & 2,49 & 2,21 & 2 & 15 & 1 & 0 & & 2,51 & 0 & 10 & 8 & 0 & \\
\hline 2013 & 7 & 2,79 & 3,12 & 2,25 & 2,02 & 1 & 6 & 0 & 0 & & 2,34 & 0 & 6 & 1 & 0 & \\
\hline 2012 & 25 & 3,91 & 3,12 & 2,37 & 2,1 & 2 & 20 & 3 & 0 & & 2,51 & 0 & 14 & 10 & 1 & \\
\hline & 74 & & & & & 8 & 55 & 11 & 0 & 0 & & 1 & 40 & 30 & 3 & 0 \\
\hline
\end{tabular}

El gráfico 4 muestra la proporción de profesores evaluados por las zonas de Santiago. Norte y Oeste representan zonas con mayor cantidad de docentes evaluados. Cordillera es la zona con menos docentes debido a la menor cantidad colegios municipales y con mayor oferta de colegios particulares. Llama la atención que la Zona Sur, que al igual que la Norte está conformada por 9 comunas, tenga tan baja cantidad de docentes.

Gráfico 4:

Cantidad de docentes evaluados según zonas pastorales de Santiago.

\section{Docentes evaluados por zonas}

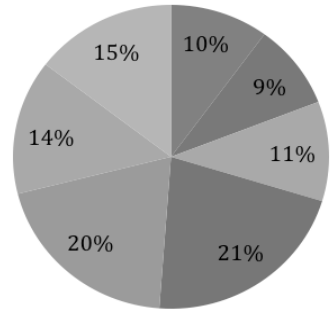

$$
\begin{aligned}
& \text { m Centro } \\
& \text { m Cordillera } \\
& \text { " Maipo } \\
& \text { " Norte } \\
& \text { m Oeste } \\
& \text { m Oriente } \\
& \text { "Sur }
\end{aligned}
$$


En todas las zonas se observa que el promedio del portafolio del año 2016 es el más alto, lo cual algunos docentes consultados lo explican como efecto del inicio del encasillamiento para entrar a la carrera docente. Esto quiere decir que los docentes tuvieron una preparación más "fuerte" para responder al instrumento.

En el histórico de los cinco años observados los profesores con desempeño Competente y Destacado en el portafolio son bajos.

Las siguientes tablas muestran los desempeños por portafolio y desempeño final por cada zona. Se suman los desempeños Insatisfactorios y Básicos y luego los Competentes y Destacados. Luego, se calculan los porcentajes.

Tabla 18:

Porcentaje de desempeño en el portafolio y ED final de la Zona Centro.

\begin{tabular}{|l|l|l|l|l|l|l|l|l|l|l|l|}
\hline \multicolumn{2}{|l|}{ ZONA CENTRO } & \multicolumn{3}{l|}{ Desempeño portafolio } & \multicolumn{3}{l|}{ Desempeño final } \\
\hline & docentes & I & B & C & D & vacía & I & B & C & D & vacía \\
\hline 2016 & 9 & & 5 & 4 & & & & 2 & 6 & 1 & \\
\hline 2015 & 20 & 2 & 16 & 1 & & 1 & & 8 & 11 & & 1 \\
\hline 2014 & 10 & 1 & 7 & 2 & & & & 3 & 7 & & \\
\hline 2013 & 2 & 1 & 1 & & & & & 1 & 1 & & \\
\hline 2012 & 10 & 1 & 9 & & & & & 5 & 5 & & \\
\hline & 51 & 5 & 38 & 7 & 0 & 1 & 0 & 19 & 30 & 1 & 1 \\
\hline & & I+B $=$ & 43 & C+D $=$ & 7 & & I+B $=$ & 19 & C+D $=$ & 31 & \\
\hline & & $\%$ & 84,3 & & 13,7 & & $\%$ & 37,3 & & 60,8 & \\
\hline
\end{tabular}

En la Zona Centro, de 84,3\% de docentes con niveles de desempeño Insatisfactorio y Básico en el portafolio, luego, en la evaluación final quedan 37,3\%, es decir, 24 docentes avanzan al nivel Competente. Igualmente, el resultado final del desempeńo es alto en comparación al resto de las zonas de Santiago. Algunos profesores de esta zona han participado en varios diplomados otorgados por la VED. 
Rolando Soto Bustos | Evaluación Docente de los Profesores de Religión Católica en Chile

Tabla 19:

Porcentaje de desempeño en el portafolio y ED final de la zona cordillera.

\begin{tabular}{|l|l|l|l|l|l|l|l|l|l|l|l|}
\hline \multicolumn{9}{|l|}{ ZONA CORDILLERA } & \multicolumn{9}{|l|}{ desempeño portafolio desempeño final } \\
\hline & docentes & I & B & C & D & vacía & I & B & C & D & vacía \\
\hline 2016 & 12 & 0 & 5 & 5 & 2 & & 0 & 0 & 7 & 5 & \\
\hline 2015 & 5 & 0 & 4 & 1 & 0 & & 0 & 0 & 4 & 1 & \\
\hline 2014 & 10 & 0 & 7 & 3 & 0 & & 0 & 3 & 7 & 0 & \\
\hline 2013 & 11 & 1 & 7 & 3 & 0 & & 1 & 3 & 4 & 3 & \\
\hline 2012 & 8 & 0 & 8 & 0 & 0 & & 0 & 3 & 4 & 1 & \\
\hline & 46 & 1 & 31 & 12 & 2 & 0 & 1 & 9 & 26 & 10 & 0 \\
\hline & & $1+B=$ & 32 & $C+D=$ & 14 & & $1+B=$ & 10 & $C+D=$ & 36 & \\
\hline & & $\%$ & 69,6 & & 30,4 & & $\%$ & 21,7 & & 78,3 & \\
\hline
\end{tabular}

En la zona cordillera se aprecia que el 78,3\% de los profesores alcanzan los niveles Competente y Destacado, que son los más altos del Arzobispado. En la realidad, el equipo de la VED ha visto que en estas comunas los profesores reciben bastante apoyo por parte de los DEM. Es probable que el nivel remuneracional sea más alto, lo cual otorga ventajas comparativas en relación a las demás zonas.

En conversación con algunos docentes de esta zona, señalan que un factor que mueve a los profesores al mejoramiento del desempeño tiene que ver con la tradición del colegio que los equipos directivos son capaces de transferir a sus profesores. Esto se traduce en una exigencia académica y de formación que los profesores interpretan como un constante impulso hacia el desarrollo profesional. A lo anterior se une el trabajo de reflexión de los profesores en consejos y reuniones pedagógicas. 
Tabla 20:

Porcentaje de desempeño en el portafolio y ED final de la zona del Maipo.

\begin{tabular}{|l|l|l|l|l|l|l|l|l|l|l|l|}
\hline \multicolumn{1}{|l|}{ ZONA del MAIPO } & \multicolumn{1}{l|}{ desempeño portafolio } & \multicolumn{3}{l|}{ desempeño final } \\
\hline & docentes & I & B & C & D & vacía & I & B & C & D & vacía \\
\hline 2016 & 10 & 2 & 2 & 6 & 0 & & 2 & 1 & 6 & 1 & \\
\hline 2015 & 6 & 2 & 3 & 1 & 0 & & 0 & 5 & 1 & 0 & \\
\hline 2014 & 16 & 1 & 12 & 3 & 0 & & 2 & 6 & 8 & 0 & \\
\hline 2013 & 6 & 0 & 5 & 0 & 1 & & 0 & 4 & 1 & 1 & \\
\hline 2012 & 16 & 2 & 12 & 2 & 0 & & 0 & 11 & 5 & 0 & \\
\hline & 54 & 7 & 34 & 12 & 1 & 0 & 4 & 27 & 21 & 2 & 0 \\
\hline & & I+B $=$ & 41 & C+D $=$ & 13 & & I+B $=$ & 31 & C+D & 23 & \\
\hline & & $\%$ & 75,9 & & 24,1 & & $\%$ & 57,4 & & 42,6 & \\
\hline
\end{tabular}

Esta zona de Santiago está compuesta por dos comunas principalmente, Puente Alto y San José de Maipo. La mayor cantidad de profesores proviene de la primera comuna, la cual tiene muchos establecimientos municipales.

Llama la atención que un cuarto de los profesores con desempeño Insatisfactorio y Básico en el portafolio logra avanzar al desempeño Competente final. Esta es una zona alejada del centro de la capital y los docentes no participan activamente de las actividades formativas de la VED. Sin embargo, la distancia no sería el único factor, ya que en los años 2015 y 2016 se realizó el Diplomado de la UFT en la zona y, a pesar de esto, hubo que invitar a otros profesores para poder llenar los cupos disponibles. Es la zona que alcanza el nivel más alto de profesores con desempeño Insatisfactorio y Básico al final de la ED (57,4\%). 
Rolando Soto Bustos | Evaluación Docente de los Profesores de Religión Católica en Chile

Tabla 21:

Porcentaje de desempeño en el portafolio y ED final de la zona Norte.

\begin{tabular}{|l|l|l|l|l|l|l|l|l|l|l|l|}
\hline \multicolumn{3}{|l|}{ ZONA NORTE } & \multicolumn{4}{|l|}{ Desempeño portafolio } & \multicolumn{3}{l|}{ Desempeño final } \\
\hline & docentes & I & B & C & D & vacía & I & B & C & D & vacía \\
\hline 2016 & 19 & 2 & 9 & 8 & 0 & & 1 & 1 & 16 & 1 & \\
\hline 2015 & 24 & 5 & 18 & 0 & 0 & 1 & 3 & 18 & 2 & & 1 \\
\hline 2014 & 17 & 0 & 16 & 1 & 0 & & 0 & 7 & 10 & 0 & \\
\hline 2013 & 16 & 3 & 11 & 2 & 0 & & 2 & 7 & 6 & 1 & \\
\hline 2012 & 33 & 6 & 26 & 1 & 0 & & 0 & 20 & 13 & 0 & \\
\hline & 109 & 16 & 80 & 12 & 0 & 1 & 6 & 53 & 47 & 2 & 1 \\
\hline & & $I+B=$ & 96 & $C+D=$ & 12 & & I+B $=$ & 59 & $C+D=$ & 49 & \\
\hline & & $\%$ & 88,1 & & 11,0 & & $\%$ & 54,1 & & 45,0 & \\
\hline
\end{tabular}

Esta zona está compuesta por 9 comunas, algunas de las cuales se encuentran bastante alejadas del centro de Santiago y de los lugares de formación (Til Til, Lampa, Colina). Si bien tiene rutas de acceso como autopistas que hacen más rápido el transporte, la distancia juega un rol al momento de participar en estas instancias. Destaca el alto número de profesores con niveles Insatisfactorio y Básico en el portafolio. Más de la mitad (54,1\%) se mantiene en los niveles más bajos al final de la ED.

Tabla 22:

Porcentaje de desempeño en el portafolio y ED final de la zona Oeste.

\begin{tabular}{|l|l|l|l|l|l|l|l|l|l|l|l|}
\hline \multicolumn{3}{|l|}{ ZONA OESTE } & \multicolumn{3}{l|}{ desempeño portafolio } & \multicolumn{3}{l|}{ desempeño final } \\
\hline & docentes & I & B & C & D & vacía & I & B & C & D & vacía \\
\hline 2016 & 17 & 0 & 11 & 6 & 0 & & 0 & 6 & 9 & 2 & \\
\hline 2015 & 11 & 0 & 10 & 1 & 0 & & 0 & 6 & 4 & 1 & \\
\hline 2014 & 20 & 2 & 18 & 0 & 0 & & 0 & 8 & 12 & 0 & \\
\hline 2013 & 20 & 5 & 13 & 2 & 0 & & 1 & 9 & 10 & 0 & \\
\hline 2012 & 33 & 6 & 26 & 1 & 0 & & 0 & 18 & 14 & 1 & \\
\hline & 101 & 13 & 78 & 10 & 0 & 0 & 1 & 47 & 49 & 4 & 0 \\
\hline & & I+B $=$ & 91 & C+D $=$ & 10 & & I+B $=$ & 48 & C+D $=$ & 53 & \\
\hline & & $\%$ & 90,1 & & 9,9 & & $\%$ & 47,5 & & 52,5 & \\
\hline
\end{tabular}


La Zona Oeste tiene el porcentaje más alto de profesores con niveles de desempeño Insatisfactorio y Básico en el portafolio (90,1\%) en comparación con las demás. Sin embargo, muchos profesores de nivel básico en el portafolio logran avanzar al nivel competente al final de la ED. Es una zona donde se han intentado hacer encuentros en diversos lugares en estos años como una forma de facilitar su acercamiento, pero no se ha logrado que se dé una instancia más permanente que consolide una comunidad con características propias.

Tabla 23:

Porcentaje de desempeño en el portafolio y ED final de la zona Oriente.

\begin{tabular}{|l|l|l|l|l|l|l|l|l|l|l|l|}
\hline \multicolumn{3}{|l|}{ ZONA ORIENTE } & \multicolumn{3}{l|}{ desempeño portafolio } & \multicolumn{5}{l|}{ desempeño final } \\
\hline & docentes & I & B & C & D & vacía & I & B & C & D & vacía \\
\hline 2016 & 13 & 2 & 5 & 4 & 2 & & 0 & 3 & 6 & 4 & \\
\hline 2015 & 13 & 1 & 12 & 0 & 0 & & 0 & 8 & 5 & 0 & \\
\hline 2014 & 10 & 1 & 6 & 3 & 0 & & 1 & 4 & 5 & 0 & \\
\hline 2013 & 18 & 2 & 14 & 2 & 0 & & 0 & 14 & 2 & 2 & \\
\hline 2012 & 19 & 1 & 16 & 2 & 0 & & 0 & 7 & 11 & 1 & \\
\hline & 73 & 7 & 53 & 11 & 2 & 0 & 1 & 36 & 29 & 7 & 0 \\
\hline & & $I+B=$ & 60 & $C+D=$ & 13 & & $1+B=$ & 37 & $C+D=$ & 36 & \\
\hline & & $\%$ & 82,2 & & 17,8 & & $\%$ & 50,7 & & 49,3 & \\
\hline
\end{tabular}

En esta zona se observa un número alto de profesores con niveles de desempeño Insatisfactorio y Básico, que luego logra subir al nivel superior de desempeño al final de la ED. El resultado final está reflejando un porcentaje muy parecido de profesores con desempeños Insatisfactorios y Básicos (50,7\%) con los Competentes y Destacados (49,3\%). Las cuatro comunas que componen esta zona tienen docentes que se evalúan año tras año, y en algunas hay bastante apoyo por parte de los DEM o existe un nivel de organización por parte de los mismos docentes. 
Rolando Soto Bustos | Evaluación Docente de los Profesores de Religión Católica en Chile

Tabla 24:

Porcentaje de desempeño en el portafolio y ED final de la zona Sur.

\begin{tabular}{|c|c|c|c|c|c|c|c|c|c|c|c|}
\hline \multicolumn{2}{|c|}{ ZONA SUR } & \multicolumn{5}{|c|}{ desempeño portafolio } & \multicolumn{5}{|c|}{ desempeño final } \\
\hline & docentes & I & B & C & D & vacía & I & B & C & D & vacía \\
\hline 2016 & 17 & 2 & 8 & 7 & 0 & & 0 & 6 & 9 & 2 & \\
\hline 2015 & 7 & 1 & 6 & 0 & 0 & & 1 & 4 & 2 & 0 & \\
\hline 2014 & 18 & 2 & 15 & 1 & 0 & & 0 & 10 & 8 & 0 & \\
\hline 2013 & 7 & 1 & 6 & 0 & 0 & & 0 & 6 & 1 & 0 & \\
\hline \multirow[t]{4}{*}{2012} & 25 & 2 & 20 & 3 & 0 & & 0 & 14 & 10 & 1 & \\
\hline & 74 & 8 & 55 & 11 & 0 & 0 & 1 & 40 & 30 & 3 & 0 \\
\hline & & $\mathrm{I}+\mathrm{B}=$ & 63 & $C+D=$ & 11 & & $\mathrm{I}+\mathrm{B}=$ & 41 & $C+D=$ & 33 & \\
\hline & & $\%$ & 85,1 & & 14,9 & & $\%$ & 55,4 & & 44,6 & \\
\hline
\end{tabular}

Finalmente, en la zona Sur también se da un alto nivel de profesores con niveles Insatisfactorios y Básicos en el desempeńo del portafolio $(85,1 \%)$ pero que logran avanzar al nivel superior al final de la ED. Sin embargo, es mayor aún el porcentaje de docentes Insatisfactorios y Básicos que los Competentes y Destacados.

Como se ha podido observar, son apenas 3 profesores Destacados en el portafolio en estos 5 años en todo Santiago, de los cuales 2 se ubican en la Zona Cordillera y 1 en la zona del Maipo. Cualquier plan de trabajo debiera significar poder contar con el apoyo de estos docentes para colaborar a mejorar las dificultades que están teniendo un gran número de docentes para responder este instrumento. 


\section{Portafolio por comunas}

La tabla 25 presenta los puntajes promedio de 4 comunas de Santiago:

Tabla 25:

Puntajes del portafolio de las comunas de Santiago, Puente Alto, La Florida y Maipú de los años 2012 a 2015.

\begin{tabular}{|c|c|c|c|c|c|c|c|c|c|c|c|c|c|c|c|c|}
\hline & \multicolumn{4}{|c|}{ Santiago } & \multicolumn{4}{|c|}{ Puente Alto } & \multicolumn{4}{|c|}{ La Florida } & \multicolumn{4}{|c|}{ Maipú } \\
\hline & $\stackrel{\frac{n}{5}}{\sim}$ & $\stackrel{ \pm}{\grave{n}}$ & $\bar{m}$ & సั & $\frac{n}{2}$ & $\stackrel{ \pm}{\circ}$ & $\bar{m}$ & $\tilde{ก}$ & $\stackrel{\frac{n}{2}}{\sim}$ & $\stackrel{\nabla}{\sim}$ & $\stackrel{m}{\bar{N}}$ & సั & $\stackrel{n}{\frac{n}{2}}$ & অ্য & 产 & $\tilde{\check{\Sigma}}$ \\
\hline $\begin{array}{l}\text { Organización } \\
\text { de la unidad }\end{array}$ & 2,13 & 2,48 & 2 & 2,25 & 2,3 & 2,28 & 2,3 & 2,11 & 2,16 & 2,2 & 2,27 & 2 & 2,14 & 2,55 & 2,45 & 2,08 \\
\hline $\begin{array}{l}\text { Análisis de la } \\
\text { clase }\end{array}$ & 1,86 & 2,01 & 1,67 & 1,81 & 1,72 & 1,79 & 2,19 & 1,7 & 2,04 & 1,86 & 2,11 & 1,83 & 1,8 & 1,83 & 1,58 & 1,47 \\
\hline $\begin{array}{l}\text { Calidad de la } \\
\text { Evaluación }\end{array}$ & 1,5 & 2 & 2 & 2,05 & 1,58 & 2,03 & 2,25 & 2,01 & 1,68 & 2,3 & 1,91 & 2,15 & 1,91 & 2 & 1,53 & 1,79 \\
\hline $\begin{array}{l}\text { Reflexión a } \\
\text { partir de la } \\
\text { Evaluación }\end{array}$ & 1,67 & 2,05 & 1,25 & 1,72 & 1,58 & 1,88 & 1,95 & 1,58 & 2,06 & 1,8 & 2 & 1,53 & 1,7 & 1,3 & 1,5 & 1,58 \\
\hline $\begin{array}{l}\text { Ambiente de } \\
\text { la clase }\end{array}$ & 2,78 & 2,66 & 2,67 & 2,56 & 2,66 & 2,82 & 2,72 & 2,7 & 2,75 & 2,6 & 2,66 & 2,75 & 2,69 & 2,61 & 2,46 & 2,66 \\
\hline $\begin{array}{l}\text { Estructura de } \\
\text { la clase }\end{array}$ & 2,64 & 2,3 & 2 & 2,4 & 2,36 & 2,35 & 2,55 & 2,48 & 2,91 & 2,53 & 2,41 & 2,41 & 2,58 & 2,11 & 2,41 & 2,08 \\
\hline $\begin{array}{l}\text { Interacción } \\
\text { Pedagógica }\end{array}$ & 2,31 & 2,5 & 1,87 & 2,05 & 2,18 & 2,3 & 2,35 & 2,25 & 2,18 & 2,5 & 2,08 & 2,12 & 2,35 & 1,91 & 2,25 & 2,12 \\
\hline
\end{tabular}

Las comunas de la tabla 25 concentran la mayor cantidad de profesores evaluados entre los años 2012 y 2015 . Representan a un tercio de los profesores evaluados.

Gráfico 5:

Puntajes del portafolio de docentes evaluados en Santiago, Puente Alto, La Florida y Maipú.

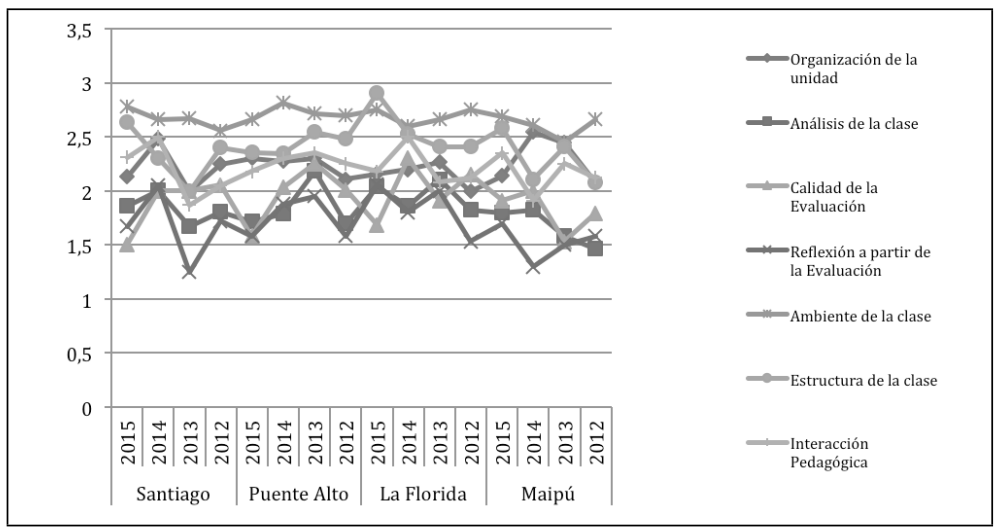


Rolando Soto Bustos | Evaluación Docente de los Profesores de Religión Católica en Chile

Según el gráfico 5, solamente la dimensión del ambiente de la clase se encuentra sobre 2,5, puntaje considerado sobre el nivel aceptado. Esta dimensión se observa en la clase grabada. A continuación, la estructura de la clase grabada tiene algunas puntuaciones elevadas, como en La Florida en el año 2015.

Muy por debajo, las dimensiones menos puntuadas son las de la Reflexión a partir de la Evaluación, la Calidad de la Evaluación y el Análisis de la Clase, todas dimensiones correspondientes al producto escrito del portafolio.

Estos resultados claramente señalan que los profesores encuentran muchas dificultades en las dimensiones medidas en el portafolio escrito, siendo la evaluación una constante en todos los profesores evaluados a lo largo de Chile.

\section{REFLEXIONES FinALES}

Este estudio ha sido realizado sobre la base de información entregada por el MINEDUC y cruzada con los datos que la Vicaría tiene a disposición en los meses de octubre a diciembre de 2017. Sería interesante continuar el análisis de cada comuna respecto de los puntajes del portafolio para ir determinando otros factores que inciden. Por ejemplo, en la zona Cordillera se concentra una gran cantidad de profesores de Religión debido a la mayor presencia de colegios católicos. Estos colegios resultan atractivos por su nivel de remuneraciones y porque permiten trabajo en equipo y formación continua, aspectos que atraen a muchos docentes a postular a dichos centros. En otras zonas claramente esto no es posible, incluso la edad promedio de los docentes es cercana a los 60 años.

También se podría complementar esta información con los resultados de la prueba de conocimientos disciplinarios y pedagógicos, que pasa a formar parte de la ED obligatoria, no voluntaria, como hasta antes de la publicación de la Ley de Desarrollo Profesional Docente. Se podrían analizar los programas de formación cursados por los docentes y las instituciones por las que han pasado. 
Como se puede observar, queda aún mucho camino por recorrer para seguir nutriendo la reflexión y el mejoramiento de la posición de la asignatura en el currículo escolar.

Con lo expuesto hasta ahora se comparten algunas reflexiones finales que permitan abrir el diálogo de los profesores, académicos, Vicarías y Conferencia Episcopal.

\section{¿Héroes, exitosos o buenos profesores?}

El año 2013, la profesora Beatrice Ávalos, Premio Nacional de Educación, publicaba un libro que llevaba como título una pregunta inquietante ¿Héroes o villanos? El libro reunía la opinión de destacados académicos e investigadores en educación del Centro de Investigación Avanzada en Educación (CIAE) respecto de estudios realizados a unos 2000 docentes.

La pregunta del libro recoge una parte de la opinión pública que tiende a culpabilizar a los docentes de la mala calidad de la educación. Suponiendo que esto sea cierto, surgen algunas preguntas: ¿los profesores son los únicos responsables de la mala calidad de la educación? ¿Qué se entiende por calidad de la educación cuando se afirma lo anterior? ¿Los resultados de las evaluaciones SIMCE y PSU miden la calidad de docentes que tienen los estudiantes? ¿Dedicarse a la pedagogía es un acto de heroísmo considerando el actual escenario? ¿El heroísmo se prueba por la voluntad y perseverancia a cambio de resultados medibles? Y podríamos seguir.

Hablar de ED es entrar en un tema difícil que tiene opiniones divididas. En un seminario organizado por la Vicaría de la Educación de Chillán ${ }^{10}$ los profesores de Religión expresaban abiertamente sus pesares, pero también los aprendizajes vividos al ser evaluados. Algunos percibían amenazas por las consecuencias laborales que ello conlleva, pero sobre todo el de ser catalogado como un mal profesor.

10 "La evaluación docente: percepciones y evidencias para un ejercicio de construcción profesional”. Chillán, 19 de diciembre de 2017. 
En ocasiones no solo es amenazante, sino que provoca espanto si los resultados de la ED son dichos por el Director del CPEIP ${ }^{11}$ en una sesión pública y ante los académicos que forman profesores en Chile.

Para muchos estos resultados de la ED de los profesores de Religión son una demostración de que la asignatura no tiene un sustento pedagógico que la avale. Sin embargo, la pedagogía es un lugar de combate (Meirieu, 2016) en la que día a día los profesores, en general, y los de Religión, en particular, intentan torcerles la mano a los agoreros de las malas noticias.

La académica López de Maturana (2016) parece distanciarse de posturas que clasifican a los profesores de exitosos y eficientes, prefiriendo hablar de los buenos profesores, ya que no todo el quehacer de un docente es eficiente. Su reflexión permite tomar distancia de los análisis cuantitativos para observar a los docentes en su trayectoria y originalidad. Cabe la posibilidad de que un profesor de Religión, reconocido por sus pares y estudiantes como un buen profesional, no tenga un resultado exitoso en la evaluación docente.

Al revisar tantas cifras y componer cuadros que hablen, se siguen formulando preguntas acerca de quiénes son estos profesores, sus esfuerzos por ser cercanos con los estudiantes, conocerlos y estimularlos para perseverar en su desarrollo como estudiantes, hijos, amigos y compañeros. En segundo plano aparece con fuerza la idea de la identidad del docente. Desde este punto de vista parece oportuno clarificar que lo que se evalúa es el desempeńo, pero en aspectos precisos con reglas que se aplican a todos los docentes. Según este planteamiento, la ED seleccionará algunas dimensiones y buscará una forma de medirlo. Habría que tener cuidado con una perspectiva que intente explicar que el éxito de la educación depende de la eficiencia

11 Seminario "Grandes desafíos en tiempos de Reforma Educativa” el 2 de junio de 2017, organizado por las Facultades de Educación del CRUCH. En dicha ocasión el Sr. Jaime Veas expresó que los profesores de Religión Católica son los que tienen el peor desempeńo del sistema (la proporción de profesores con desempeño Insatisfactorio y Básico alcanza al 88,85\% de los profesores de la asignatura). 
de los docentes demostrado en las cifras que aquí aparecen. Son un dato y hay que considerarlo, pero sin dogmatizar su contenido.

\section{La experiencia es el lugar de los profesores / la ED y la MBE son pura teoría}

El último estudio de MideUC sobre percepciones y experiencias de docentes en torno a la ED, los investigadores Sun et all sostienen que "para muchos profesores, la ED pertenece a un espacio ajeno a su práctica cotidiana y, para enfrentarla con éxito, suponen que deben emplear elementos también ajenos" (2017, p. 2). Para algunos, tanto el MBE como la ED son dos planteamientos teóricos que no se ajustan a su realidad. Se hace necesario que los docentes abandonen posiciones que lo tienen anclado a su propia experiencia y que puedan reconocer el conocimiento teórico como un aporte a su práctica. En esto no ayuda seguir afirmando que la clase de Religión es diferente, ya que también lo es música y educación física. Quizás habría que decir que es una originalidad.

Se hace necesario profundizar la mirada sobre la ED y su contribución al desarrollo profesional de los profesores de Religión. Al reunirse los profesores de Religión en los talleres que organiza la Vicaría da la impresión que, más que promover un progreso en lo pedagógico, se tiende a resolver un problema puntual de cómo responder el portafolio. La mirada debe ir más allá de lo instrumental para redescubrir el encantamiento con la pedagogía y la educación.

Volviendo sobre la experiencia del docente, se debe considerar también una instancia que les permita a los profesores transitar a la teoría sin percibir que está perdiendo el arte y la poesía del oficio. La riqueza de su experiencia debe ser tomada en cuenta y ayudarle a revisarla a la luz del conocimiento pedagógico. Esto debiera ser lo propio de los estudios de postgrado a la que los profesores debieran aspirar, pero que por ahora se ve imposible de gestionar por parte de la Vicaría.

Aprender a leer la propia ED como un instrumento que ayuda a los profesores a realizar una reflexión pedagógica implica reconocer 
Rolando Soto Bustos | Evaluación Docente de los Profesores de Religión Católica en Chile

que esta información es válida. Algunos profesores han podido compartir en el seminario de Chillán que sí es posible realizar el tránsito entre la experiencia y la teoría.

Sin embargo, no se cuenta con un estudio que permita concluir categóricamente cuál es la percepción que tienen los profesores de Religión de la ED. Algunos profesores han expresado que el informe individual de fortalezas y debilidades de la ED tenía indicaciones demasiado generales que no se ajustaban a cada caso en general. Un profesor de Religión que trabaja en el equipo de corrección de Mide UC señala que se ha ido mejorando cada vez más los instrumentos y el reporte hacia los docentes.

Especial cuidado merece la información que entrega el portafolio ya que se evidencian dimensiones muy poco trabajadas por los docentes. En este sentido, el tema de la evaluación de aprendizajes debe preocupar muchísimo ya que prácticamente sus resultados son históricamente bajos.

Otra dimensión teórica que es necesario aterrizar con los docentes tiene que ver con el MBE. Es necesario tener en cuenta que el MINEDUC se encuentra estudiando su modificación, lo cual podría estar operativo para el siguiente proceso del año 2018. Esto puede implicar una revisión de los procesos de acompańamiento a los profesores de Religión, ya que según el nuevo marco se ajustará también la ED. Igualmente será necesaria una revisión profunda del nuevo marco para orientar a los profesores respecto de nomenclatura y criterios para su trabajo en el aula.

\section{Competencias pedagógicas disminuidas}

La experiencia del Equipo de Pedagogía en Religión de la Vicaría ha contemplado talleres con docentes que están en proceso de ED. Los profesores que asisten tienen conocimiento del MBE, pero en su implementación se percibe un manejo no reflexivo de los criterios y descriptores, en otros casos se observa inseguridad o un conocimiento básico, lo que lleva a concluir lo mismo que sostienen Fuentealba e 
Imbarack (2015), que los conocimientos pedagógicos se encuentran disminuidos en los profesores de Religión.

Esto no quiere decir que los profesores solamente requieren conocer y dominar técnicas y metodologías, lo cual sería un contrasentido e iría en contra de lo postulado más arriba. Se trata de conformar una identidad docente en la que lo pedagógico surge como consecuencia de principios sobre la naturaleza de lo que enseńa y de los destinatarios de la formación.

Tampoco se trata de aplicar estrategias de innovación, tan en boga por estos días, sin reflexionar previamente en qué consiste enseñar Religión y cómo entender el aprendizaje de la educación religiosa. Este parece ser un punto esencial para el trabajo posterior con los profesores.

\section{Teólogos escolares/pedagogos}

En coherencia con lo anterior surge una pista que es necesario indagar con mayor profundidad con los centros de formación de docentes. Conjuntamente con la necesidad de comprender la naturaleza de la educación religiosa escolar en el currículo se debe otorgar el sentido pedagógico de la asignatura de Religión en la escuela. Ambas perspectivas deben avanzar unidas, sin embargo, esta propuesta no está exenta de obstáculos.

Un pedagogo decía que el saber precede al aprender y pedagógicamente el sujeto precede al saber (Meirieu, 2016). En esta doble vertiente el docente debe aprender a hacer su oficio. Algunas voces consideran que la pedagogía en Religión sería más fecunda con más teología, mientras otros ponen el acento en más pedagogía. Para unos el docente sería un teólogo escolar y para otros un formador de niños y jóvenes. Las posiciones son sutiles, pero es necesario profundizar en este campo. La tarea consiste en aprender significativamente el saber disciplinar y pedagógico para formar a niños y jóvenes en su dimensión religiosa.

Es necesario revisar el perfil del profesor de Religión según los estándares de formación inicial que el MINEDUC ha ido elaborando. 
Rolando Soto Bustos | Evaluación Docente de los Profesores de Religión Católica en Chile

Existe en el CPEIP un área de trabajo que está elaborando nuevos perfiles que sin duda no abarcan al profesor de religión. El estudio de estos estándares puede provocar una mayor reflexión respecto del dominio de la disciplina y de los conocimientos pedagógicos que debe contener la malla curricular de los profesores de Religión, sin descuidar cómo hacer un plan para docentes en ejercicio que son de otra generación.

\section{Fortalecerse en la identidad docente}

De cara a la ED, la Vicaría debe tener una mirada pastoral, además de la académica, como agente educativo especializado en el área que le compete. Su trabajo consiste en el acompañamiento de los docentes respecto de su rol profesional. Existen documentos en los que la Iglesia ha insistido en el perfil del profesor de Religión, como un educador católico en la escuela, creyente, orante y testigo, entre otras características. A veces, se ha acentuado más el pastoral y menos el pedagógico.

Los profesores buscan ser reconocidos como profesionales de la educación y esperan que su experiencia sea validada. Pero, más aún, desean contribuir a la educación del país, tarea en la cual necesitan ser reencantados, como decía una profesora de Providencia.

$\mathrm{Al}$ analizar los resultados de la ED se busca comprender qué se entiende por desarrollo profesional, poniendo atención, también, a la voz de los docentes. El desafío será siempre la dignificación de la profesión docente, estando atento a posturas que intentan encapsular a la pedagogía y a los profesores como meros técnicos o reproductores del currículo.

\section{Tareas de corresponsabilidad}

La Ley 20.903 de Carrera Docente asume una serie de principios que intentan persuadir al profesor respecto de su responsabilidad con la profesión que ejerce. Busca que el docente adhiera conscientemente a un camino de constante reflexión respecto de su práctica. Nadie 
puede hacer este camino por él. La institucionalidad ha creado medios que deben movilizar la voluntad hacia la búsqueda de la excelencia pedagógica.

No obstante, el camino pedagógico está plagado de situaciones cotidianas que afectan el trabajo docente. Existe un círculo vicioso del cual el docente forma parte, al igual que otros actores educativos, que es necesario reconocer para evitar caer en él. Se basa en la creencia de que las familias no educan bien a los niños, el equipo directivo no apoya a los profesores, que la sociedad enajena a los estudiantes y que los colegas no toman en cuenta la asignatura de Religión.

Todos estos factores tienen un sustento en la realidad, no son invento de los profesores, pero juegan un rol fundamental en el rol del docente. Quizás el último factor sea más que una percepción, ya que para muchos es una realidad inobjetable. De ello hay muchos documentos que hablan de una escasa valoración del medio hacia la clase de Religión.

Sin embargo, también es cierto que el profesor es el profesional que entra en el aula y tiene autoridad respecto de lo que hace. Quizás sea necesario que reflexione si entrar pidiendo permiso para educar o creer que todos deben ponerle atención porque él sabe más que los estudiantes no sea la mejor de las actitudes para comenzar un proceso.

Se hace necesario recordar que la profesionalización de los docentes es un camino abierto, nunca cerrado. Si hay algo que la ED ha relevado tiene que ver con la necesidad de reflexión de los profesores respecto de los procesos pedagógicos. Sabemos que ella debe darse en condiciones que permitan el intercambio con otros, en ambientes de escucha y respeto. Si el profesor de Religión es el único docente especializado en la escuela y nunca participa en la toma de decisiones, no podrá avanzar en su desarrollo.

El Director del Instituto Paulo Freire en Chile, profesor Rodrigo Vera, decía que la institucionalidad de la Ley puede facilitar los medios, pero sin el concepto de corresponsabilidad la Ley puede ser letra muerta (s/a, 2017). El profesor debe creer en que su disciplina es un motor de desarrollo para los estudiantes. Pero, al mismo tiempo, 
Rolando Soto Bustos | Evaluación Docente de los Profesores de Religión Católica en Chile

no puede quedarse en que lo sabe todo y que no tiene necesidad de seguir aprendiendo.

Ahora bien, es necesario que la Iglesia, que es quien los envía a la escuela, asuma también su responsabilidad para ofrecer instancias de formación continua. La alianza con las Facultades de Educación y Teología de las Universidades Católicas son muy necesarias para apoyar a los profesores que se quejan de no tener dónde acudir. Pero también es necesario que los profesores se organicen, asuman un rol protagónico como profesionales. Creación de comunidades de aprendizaje, grupos de reflexión y experiencias de colaboración son necesarias que surjan entre los mismos docentes. La Vicaría pueden apoyar estas iniciativas a través de profesionales que puedan acompañar y guiar los procesos.

Por las consecuencias que tiene para el desarrollo profesional de los docentes es necesario reflexionar acerca de qué planes o modalidades la Vicaría puede ayudar a los docentes que se evalúan año tras año. También puede ser necesario preguntarse por la responsabilidad de la Vicaría y de las Universidades que forman profesores de Religión. Al mismo tiempo, es vital que los profesores asuman corresponsablemente su carácter profesional para buscar instancias de formación que le permitan acrecentar sus conocimientos pedagógicos.

En cuanto a cursos de perfeccionamiento, muchos docentes reclaman que estos sean atingentes a la especialidad, con profesores que conozcan la pedagogía en Religión y con certificación CPEIP. Las voces docentes son totalmente comprensibles en este último punto, ya que en el sistema municipal existe un reconocimiento cuando el perfeccionamiento ha sido otorgado por un programa acreditado por el CPEIP. Sobre cursos especiales para profesores de Religión hay que cuidar que estos sean de profundización teológica y pedagógica. En cuanto a lo teológico, deben promover la reflexión y el pensamiento autónomo. En lo pedagógico, se espera algo similar, pero existen voces diferentes respecto del modo. Algunos desean que estos cursos sean exclusivos para profesores de Religión, mientras otros no hacen diferencias con las demás asignaturas. Quienes defienden la opción de 
cursos exclusivos consideran que la asignatura requiere un abordaje diferente que se profundizaría mejor entre docentes del área. La otra postura defiende la idea de que para mejorar en lo pedagógico es necesario dialogar con las demás asignaturas.

\section{Trabajo colaborativo}

La ED ha incorporado un módulo destinado a medir el trabajo colaborativo de los docentes, lo cual es señal de que los instrumentos están en permanente reflexión de los cambios sociales. Los docentes que preparan su portafolio lo hacen buscando apoyos en grupos de pares. A veces los colegios destinan a profesores con más experiencia para que trabajen con los docentes que están en esta situación. Sin embargo, el foco de la colaboración es otro, ya que apunta al aprendizaje de los estudiantes.

La colaboración no solo puede ocurrir entre docentes del mismo establecimiento, sino que puede hacerse entre docentes de la misma asignatura en proyectos que cada uno realiza en su establecimiento.

Sería muy interesante, aunque puede ser poco realista, que grupos de profesores de Religión trabajen en redes de apoyo y creativamente creen unidades de aprendizaje con la asesoría de la Vicaría. Esto implica potenciar las comunidades de aprendizaje que deben pasar a otra fase de trabajo.

Existen experiencias en el CPEIP de comunidades que han nacido espontáneamente por el interés de los mismos docentes, a veces motivados por investigaciones de postgrado, para pensar en resolver problemas didácticos de la disciplina.

Esto implica romper el aislamiento y el individualismo en los profesores. El aporte del trabajo colaborativo es un camino interesante que merece ser reflexionado más aún. Alentar proyectos que permitan que los docentes intercambien experiencias de prácticas pedagógicas y aumente la capacidad reflexiva sobre el enfoque de la asignatura, la didáctica y los estudiantes podrían ser parte de iniciativas que podrían esperarse a partir de informes sobre la evaluación docente. 
Rolando Soto Bustos | Evaluación Docente de los Profesores de Religión

Católica en Chile

\section{REFERENCIAS BIBLIOGRÁFICAS}

Ávalos, B. (2013). ¿Héroes o villanos? La profesión docente en Chile, Santiago, Chile: Editorial Universitaria.

Comisión de trabajo para la mejora de la EREC en Chile. (2017). Reporte de resultados de encuesta nacional aplicada a los profesores de religión. Rescatado de: http://www.clasedereligion. cl/documentos/Presentacion_resultados_encuesta_docentes.pdf

Fuentealba, R. e Imbarack, P. (2015). Una mirada a la enseñanza de la religión católica en Chile: hablemos de profesionalidad docente. En Imbarack, P. (Ed.), Educación Católica en Chile. Perspectivas, aportes y tensiones (343-365). Santiago, Chile: Ediciones UC.

Herrada, M. y Zapata, A. (2015) ¿Qué nos dice el portafolio acerca de las mejoras en el desempeño docente? Midevidencias, 1, 1-7. Extraído de: http://www.mideuc.cl/wp-content/uploads/2015/06/ MidEvidencias-N1.pdf

Ministerio de Educación (2016). Ley N² 20.903. Establece el Sistema de Desarrollo Profesional Docente. Diario oficial de la República de Chile. Rescatado de https://www.leychile.cl/ Navegar?idNorma $=1087343$

López de Maturana, S. (2016). Los buenos profesores. 3a . ed., La Serena, Chile: Editorial Universidad de la Serena.

Meirieu, P. (2016). Recuperar la pedagogía: de lugares comunes a conceptos claves. $1^{\mathrm{a}} \mathrm{ed}$. Buenos Aires, Argentina: Paidos.

s/a, (2017), Entrevista a Rodrigo Vera Godoy: "La Ley 20.903 requiere ser entendida como una convocatoria a la profesionalización de la práctica educativa”. Perspectiva. Revista Digital Docente. Extraído de http://revistaperspectiva.cl/la-ley-20-903-requiereser-entendida-como-una-convocatoria-a-la-profesionalizacionde-la-practica-educativa/ 
Sun, T., Levy, D., Cortés, O., Ramos, J. y Rojas, M. (2017) ¿Cómo son las percepciones y experiencias de docentes y directivos en torno a la Evaluación Docente? Midevidencias, 14, 1-8. Extraído de: http://mideuc.cl/wp-content/uploads/2017/midEvidencias-N14.pdf.

Sun, Y., Correa, M., Zapata, A. y Carrasco, D. (2011) Resultados: qué dice la Evaluación Docente acerca de la enseñanza en Chile. En Manzi, J., González, R. y Sun, Y., La Evaluación Docente en Chile, (93-135). Santiago, Chile: Mide UC-Pontificia Universidad Católica de Chile.

Fecha de recepción: 1 de julio de 2018

Fecha de aceptación: 3 de julio de 2018 